NBER WORKING PAPER SERIES

\title{
THE GENDERED SPILLOVER EFFECT OF YOUNG CHILDREN'S HEALTH ON HUMAN CAPITAL: EVIDENCE FROM TURKEY
}

\author{
Marcella Alsan \\ Working Paper 23702 \\ http://www.nber.org/papers/w23702 \\ NATIONAL BUREAU OF ECONOMIC RESEARCH \\ 1050 Massachusetts Avenue \\ Cambridge, MA 02138 \\ August 2017
}

I am grateful to Nava Ashraf, Martha Bailey, Jay Bhattacharya, Marshall Burke, Kasey Buckles, Lorenzo Casaburi, Resul Cesur, Gabriella Conti, Janet Currie, David Cutler, Pascaline Dupas, Eric Edmonds, Karen Eggleston, Marcel Fafchamps, Paul Gertler, Jeremy Goldhaber-Feibert, Claudia Goldin, Victor Lavy, Ron Lee, Grant Miller, Melanie Morten, Nathan Nunn, Petra Persson, Maria Polyakova, Mark Rosenzweig, Simone Schaner, Bryce Millet Steinberg, Atheendar Venkataramani, Marianne Wanamaker and seminar participants at Stanford Junior Faculty Lunch, NBER Health and Aging Doctoral Fellowship Lunch, PacDev 2015, Paris School of Economics, Toulouse School of Economics, NBER Children's Summer Institute 2015 and ASSA 2016. I am grateful to Mario Javier Carrillo and Anlu Xing for assistance, Hacettepe University and Professor Julide Yildirim of TED University for providing data and Vedat Alsan for translation. Research support gratefully acknowledged from the National Institutes of Health Eunice Kennedy Shriver National Institute of Child Health and Human Development (1K01HD084709-01, PI Alsan). First draft 2013 - since that time data have been updated on IPUMS and herein. All errors are my own. The views expressed herein are those of the author and do not necessarily reflect the views of the National Bureau of Economic Research.

NBER working papers are circulated for discussion and comment purposes. They have not been peer-reviewed or been subject to the review by the NBER Board of Directors that accompanies official NBER publications.

(C) 2017 by Marcella Alsan. All rights reserved. Short sections of text, not to exceed two paragraphs, may be quoted without explicit permission provided that full credit, including () notice, is given to the source. 
The Gendered Spillover Effect of Young Children's Health on Human Capital: Evidence from

Turkey

Marcella Alsan

NBER Working Paper No. 23702

August 2017

JEL No. I25,J16,O15

\begin{abstract}
Recent policy debates on closing the education gender gap in developing countries have focused on cash transfers, but standard models of intrahousehold allocation imply that reducing the opportunity cost of girls' schooling might also be effective. I test this prediction using quasiexperimental variation from a national vaccination campaign targeting under-five children in Turkey. I find gains in health and human capital among age-eligible children of both sexes. However, educational spillover effects accrue exclusively to their adolescent, ineligible sisters. These spillover effects are increasing if the mother works outside the home and in the number of young children in the household, and are absent if an elder sister is present. My results suggest reducing morbidity among preschool children may have the added benefit of improving educational outcomes for their adolescent sisters in the developing world
\end{abstract}

Marcella Alsan

Stanford Medical School

Center for Health Policy/PCOR

117 Encina Commons, Room 218

Stanford, CA 94304

and NBER

malsan@stanford.edu 


\section{Introduction}

Gender equity is an important development goal and various policies have been advocated for its achievement (see review by Duflo (2012)). Many of these policies are aimed at increasing girls' education, since female education has been correlated with later and lower childbearing, improved parenting, and higher labor market participation among women 1 Common policy instruments include subsidized schooling, affirmative action and conditional cash transfers. Yet in many developing countries, a gendered division of labor starts early and places the burden of household activities (including childcare) on older girls.2 The combination of such norms with high frequency morbidity among young children in developing countries could therefore meaningfully affect the educational experience of their older sisters.

Evidence consistent with this mechanism is presented in Figure 1 which demonstrates that, for Turkish children 11 to 14 years of age, the schooling gap between adolescent boys and girls increases in illness episodes experienced by younger children in the household. A similar pattern is found when using Demographic and Health surveys around the world and conditioning on household fixed effects (Alsan, Xing, Wise, Darmstadt, and Bendavid, 2017).

\section{Figure 1. Gender Schooling Gap \& Child Illness}

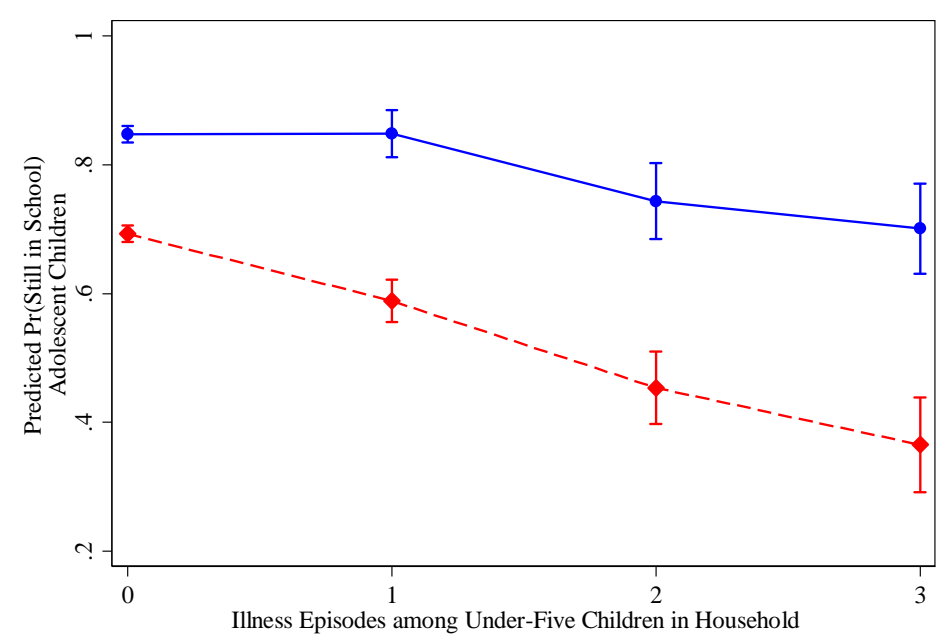

\footnotetext{
${ }^{1}$ The literature to cite here is vast, but recent summaries include World Bank (2012), Schultz $(2002)$ and Alsan, Bhadelia, Foo, Haberland, and Knaul (2016).

${ }^{2}$ Other studies which have investigated cross-sibling effects of health endowments or shocks tend to focus on whether parental investments reinforce or compensate for these differences. For recent examples see Yi, Heckman, Zhang, and Conti (2015), Parman (2013) and Adhvaryu and Nyshadham (2014). Ozier (Forthcoming) investigated spillover effects of the deworming treatment by Miguel and Kremer (2004) in Kenya on unborn children several years later. Black, Breining, Figlio, Guryan, Karbownkik, Nielsen, Roth, and Simonsen (2017) investigate whether birth order gaps are excacerbated when a disabled younger child enters the household. Seminal theoretical contributions include Becker and Tomes (1979) and Behrman, Pollak, and Taubman (1982).
} 
Notes: Data are from the Turkish Demographic and Health Surveys (1993 1998 and 2003).

The notion that older sisters' education is particularly sensitive to younger siblings' health was first articulated by Rosenzweig and Pitt (1990, p. 970) : "A natural question is whether changes in infant morbidity would significantly affect the disparities in the intrafamily allocation of activities by sex...and thus whether observed gender inequality in human capital would be reduced through improvements in child health." However, Pitt and Rosenzweig underscored this hypothesis was not easily testable since instruments that affect children's health exclusively were difficult to find.

This paper aims to fill this gap in the literature and formally test the hypothesis that the gender gap in education is affected by early childhood health in developing countries. I exploit one of the most successful and largest mass vaccination campaigns in recent history - the Turkish National Immunization Campaign of 1985. The campaign sought to immunize Turkish children under five against a battery of infectious diseases. The size of the under-five population targeted and the number of diseases included in the effort (measles, polio, as well as diphtheria, pertussis and tetanus (DPT)) were ambitious and the logistical accomplishments of the campaign unprecedented. Within three months 27 million vaccines had been administered; coverage for measles vaccine increased from 37 to $83 \%$ nationwide and a similarly impressive jump was noted for DPT vaccination.

The empirical strategy adopted exploits heterogeneity in the pre-campaign prevalence of vaccine preventable illness to compare areas that experienced a relatively larger gain in coverage to areas that experienced a more modest increase. The strategy developed in the paper corrects for underreporting of vital events which is particularly severe in rural areas and presents an obstacle to impact evaluation in developing countries $\mathrm{H}^{3}$ The greatest threat to the validity of the analysis is that vaccine preventable disease (VPD) prevalence is not randomly assigned. High VPD prevalence in the pre-campaign period is correlated with low literacy and socioeconomic status unconditionally - and such areas could be on a different time path than areas with less prevalent disease. I provide evidence that VPD prevalence is uncorrelated with almost all pre-campaign covariates prior to the rollout of the intervention conditional on other covariates. In the main analysis, province fixed effects control for time-invariant unobservables that are correlated with high VPD. Moreover, the changes that occur are specific to 1985: placebo intervention dates for the campaign fail to produce similar results.

The immunization campaign did not achieve its stated goal of reducing infant or child mortality. Reasons for the null effect are discussed, with the most likely one being that vaccine preventable illnesses were not a leading cause of mortality for this age group at

\footnotetext{
${ }^{3}$ The UN estimates that only $65 \%$ of births and one-third of all deaths are recorded through civil registration throughout the world (Mikkelsen, Lopez, and Phillips, 2015).
} 
the time. ${ }^{4}$ However, there were declines in disability and gains in schooling for age-eligible children as measured in their young adult life. A one standard deviation increase in VPD prevalence during the pre-campaign period is associated with a $5 \%$ decline in disability, a $3 \%$ increase in literacy and a $2 \%$ increase in educational attainment. These findings are robust to a range of controls thought to influence children's health and education at the individual, household and local geographic level such as maternal literacy, family structure, father's occupation and health care supply. The results are not driven by mean reversion or a specific geographic subsample of the country. The effect of the campaign on disability for age-eligible children is similar for boys and girls, consistent with official reports on widespread vaccine dissemination, but educational returns are highest for girls with siblings. ${ }^{5}$

To explore these gender-specific effects in more detail and isolate spillover effects, I examine the effect of the campaign on older siblings who were not targeted ${ }^{6}$ I find older sisters living with an age-eligible child improve their literacy and educational attainment, while older brothers do not. Data from the Demographic and Health Surveys (DHS) in Turkey and government enrollment statistics reveal where in the years of schooling distribution girls gained. The results show that more girls were induced to attend school on the extensive margin and to complete the "compulsory" education heavily subsidized by the state.

The results are interpreted within a model of the intrahousehold distribution of resources across children. In an environment where parents seek to maximize the expected earnings of their children, and the human capital of the youngest children require inputs of time, parents must choose how much time an older sibling may spend in school and how much time he/she spends performing childcare and other household activities. If there are lower returns to girls' schooling in the labor market, parents will demand less schooling for their daughters than their sons. Furthermore, if the opportunity cost of time in school increases more for girls than boys when a younger sibling is sick, due to a gendered division of labor in the home and substitutability between mother and older daughter (Rosenzweig, 1980), then illness shocks among young children will exacerbate the gender gap in education.

Several findings support the notion that opportunity costs and gender norms in household labor play a key role in the behavioral mechanism underpinning the empirical results. First, the differential gendered effect is increasing in the number of young children in the household

\footnotetext{
${ }^{4}$ Results on mortality might be more impressive for the rollout of pneumococcal and rotavirus vaccination (since pneumonia and diarrhea are the leading causes of child mortality in developing countries). More recent research suggests the measles virus suppresses the immune system by attacking memory B cells and could leave a long lasting impact on the ability of individuals to fight many different types of infections (Mina, Metcalf, de Swart, Osterhaus, and Grenfell, 2015). The implication is that measles vaccination therefore protects against other common illnesses which would require childcare.

${ }^{5}$ Vaccination of older siblings is protective for the health of younger children though the converse is not necessarily true, since older children typically have acquired natural immunity by school age.

${ }^{6}$ I use the term "spillover" to refer to gains that are not directly related to receipt of the vaccine. Although older age children might also benefit from herd immunity - and this might be larger for girls than boys if they are tasked with childcare, this does not appear to be the main explanation for my findings given the U-shaped age pattern of vaccine preventable illness morbidity. See section 4 .
} 
and muted if there are no age-eligible children in the household. Second, the gendered spillover effect is greater if the supply of maternal domestic time is limited by work outside the home, particularly in cotton fields. Third, the gendered spillover effect is absent among households with grandmothers or other older sisters, potential substitutes for a mothers' domestic time.

The model and the paper focus on time. Of course, less illness in a household also lowers medical expenditures and increases household income. Although primary schooling in Turkey was free, parents may simply prefer educating boys on average, thus marginal changes in income should affect daughters' education more than sons'. I argue the income channel is less plausible since the positive wealth shock to the household from reduced morbidity of an under-five child is small. Child illness episodes treated in the public sector are heavily subsidized but require time to travel, wait and stay with a child if hospitalized or follow instructions to care for the sick child at home.7 Empirically, I do not find significant impacts of the campaign on parental occupational status. The notion that time is a key determinant of child health in developing countries was highlighted in Miller and Urdinola (2010) and in the 1985 UNICEF State of the World's Children Report (UNICEF, 1985) $!^{8}$

This paper draws upon research at the intersection of infectious disease, children's health, gender and development. It contributes to the body of scholarship developed by Doug Almond, Janet Currie, Paul Gertler and others on child development and later life economic outcomes $9^{9}$ It provides an additional explanation for the rise of female schooling. Becker, Hubbard, and Murphy (2010) focus on female comparative advantage in noncognitive skills as the driving force. Pitt, Rosenzweig, and Hassan (2012) adapt the Roy model of occupational choice. In their model, health investments predict larger schooling gains for girl than boy children since health increases returns to labor in the brawn economy, increasing the opportunity cost of boys' schooling. This paper complements such an explanation, emphasizing how technological advances in child health will disproportionately impact the time budget of those primarily tasked with caring for them when they are ill. The paper also touches on debates about how to close the gender gap in developing countries. Much focus has been on the relative merits of gender-specific affirmative action policies and economic growth. The findings herein point to improved child health as another potential policy tool.

\footnotetext{
${ }^{7}$ In 1961, Turkey passed a law to socialize it's health service ("Statute of Socialization of Health Services"). Socialization was defined as providing free services at the point of delivery (with the exception of the cost of drugs), and collecting premiums to pay for the services. The collection of premiums was never implemented, but health centers linked to hospitals for provision of primary care were established and staffed by doctors (recent medical graduates) who were assigned two years compulsory service after graduation (Fisek and Erdal, 1985, Topalli, 2015). Other mechanisms (e.g. epidemiologic spillovers and taste-based discrimination) are considered below but cannot sufficiently explain the spillover results.

${ }^{8}$ Although time may be less important in developed countries, there is still strong evidence of a gendered division of parental responsibility for childrens' health. According to a recent Kaiser Health Survey in the United States, $81 \%$ of mothers report they are responsible for assuring a child receives recommended care. Among working parents with children under 18 in the home, $39 \%$ of mothers (compared to $3 \%$ of fathers) report primary responsibility for taking care of children when they are sick (Kaiser Family Foundation, 2014).

${ }^{9}$ See Almond (2006); Almond and Currie (2011) and Gertler, Levine, and Ames (2004).
} 
The structure of the rest of the paper is as follows: section 2 describes the campaign and gendered patterns of time use; section 3 introduces the theoretical framework used to motivate and interpret the results; section 4 describes the identification strategy and the data; section 5 presents the results. Section 6 discusses underlying biological pathways and competing explanations. Section 7 concludes.

\section{Background}

\subsection{Turkish National Immunization Campaign}

In 1980, Jim P. Grant became UNICEF director and shortly thereafter unveiled an initiative known as the child survival revolution which was based on four simple strategies: Growth Monitoring, Oral Rehydration, Breastfeeding and Immunizations (GOBI) ${ }^{10}$ As part of the revolution, Grant was searching for a low-resource country that would serve as a showcase for a successful mass immunization campaign. Grant sought out Turgut Özal, a colleague from his days at USAID, and a man who had subsequently gone on to become Turkey's prime minister. Özal agreed with the concept and the planning began. As described in a subsequent UNICEF report, the campaign "had a clear aim: to show that a large middle-income country with high infant mortality and barely average EPI coverage could inexpensively vaccinate at least $80 \%$ of its children - despite barriers of weather, terrain, and population dispersion" UNICEF, 1986, page 7) ${ }^{11}$

The campaign began with then Turkish President Kenan Evren vaccinating a baby in front of the press. This launched the first ten day campaign, with two more occurring before the end of the year. The campaign involved an impressive collaboration across sectors. Widespread media messages were conveyed by the press. Imams were given a prepared sermon to deliver from 54,000 mosques throughout the country on the Friday evening before campaign launch which quoted text on the importance of caring for children from the Quran $\left[\begin{array}{l}12 \\ \text { "Not }\end{array}\right.$

\footnotetext{
${ }^{10}$ This section draws heavily on the following publications:

"Rapid Assessment: Turkish National Immunization Campaign of 1985" (UNICEF, 1986), "Report of the Baseline Survey for the 1985 Turkish National Immunization Campaign" (Tunçbilek, Cerit, Unalan, Akadli, and Toros, 1985) and "The Vaccination Situation of Children Between 0-5 Years of Age After the Accelerated Vaccination Campaign and a Comparison with Pre-Campaign Results" (Tunçbilek, E et al., 1986). Unfortunately, only the published results from the baseline survey are available and they are compared to the reconstructed variable in Appendix Figure B3.

${ }^{11}$ Other mass vaccination campaigns include Brazil (1980 to 1985), India (1985) and Burkina Faso (late 1984). However, the Brazil campaign only included polio vaccination, the India campaign was instituted by private doctors, and the Burkina Faso campaign also had a primary health care component. The 1985 Turkish campaign is therefore unique in its scale, number of different types of vaccines delivered, use of the public sector and focus on child health (Barron, Buch, Behr, and Crisp, 1987). Though other vaccination campaigns had been carried out in Turkey prior to 1985, they were not nearly as large scale or well coordinated, typically only serving small areas. Furthermore, to the extent such campaigns were delivered effectively (and I have no evidence to suggest they were), they will be incorporated into the baseline measure of VPD prevalence used in the empirical strategy. I thank Resul Cesur for the comment.

${ }^{12}$ See Appendix Figure B1 for photos of the campaign.
} 
to miss one single child," became a national motto. Turkish Radio and Television donated free air time and an average of six articles were carried in the main national newspapers every day until the campaign's end. Healthcare workers (physicians and paramedicals) were trained and the cold chain infrastructure was bolstered with private and public donations. The target population pre-campaign was estimated at 5.1 million children between 0 and 60 months. There were over 45,000 vaccination stations aimed at being within a 10-15 minute travel time from each home. Health centers, mosques and schools as well as a few businesses served as vaccination sites.

Table 1. Coverage of Eligible Population

\begin{tabular}{llcc}
\hline Vaccine & \multicolumn{1}{c}{ Age Group } & Pre $(\%)$ & Post $(\%)$ \\
\hline DPT & $2-11$ months & 28 & 92 \\
$\&$ & $12-59$ months & 52 & 94 \\
OPV & total & 47 & 94 \\
& & & \\
& $2-11$ months & 12 & 72 \\
Measles & $12-59$ months & 40 & 84 \\
& total & 37 & 83 \\
\hline
\end{tabular}

Notes: Data taken from "Rapid Assessment: UNICEF Report of the Turkish National Immunization Campaign" (UNICEF, 1986).

Table 1 reports increased vaccine coverage among the target population of children under 60 months before and after the campaign. Figure 2 plots health outcome measures over time. Panel A demonstrates a strong downward trend in infant mortality that antedates the vaccination campaign and is in contrast to Appendix Figure B2 Panel A which shows a discontinuous drop in vaccine preventable deaths in 1985. The decline in disability in Figure 2 Panel B occurs contemporaneous with the campaign. 


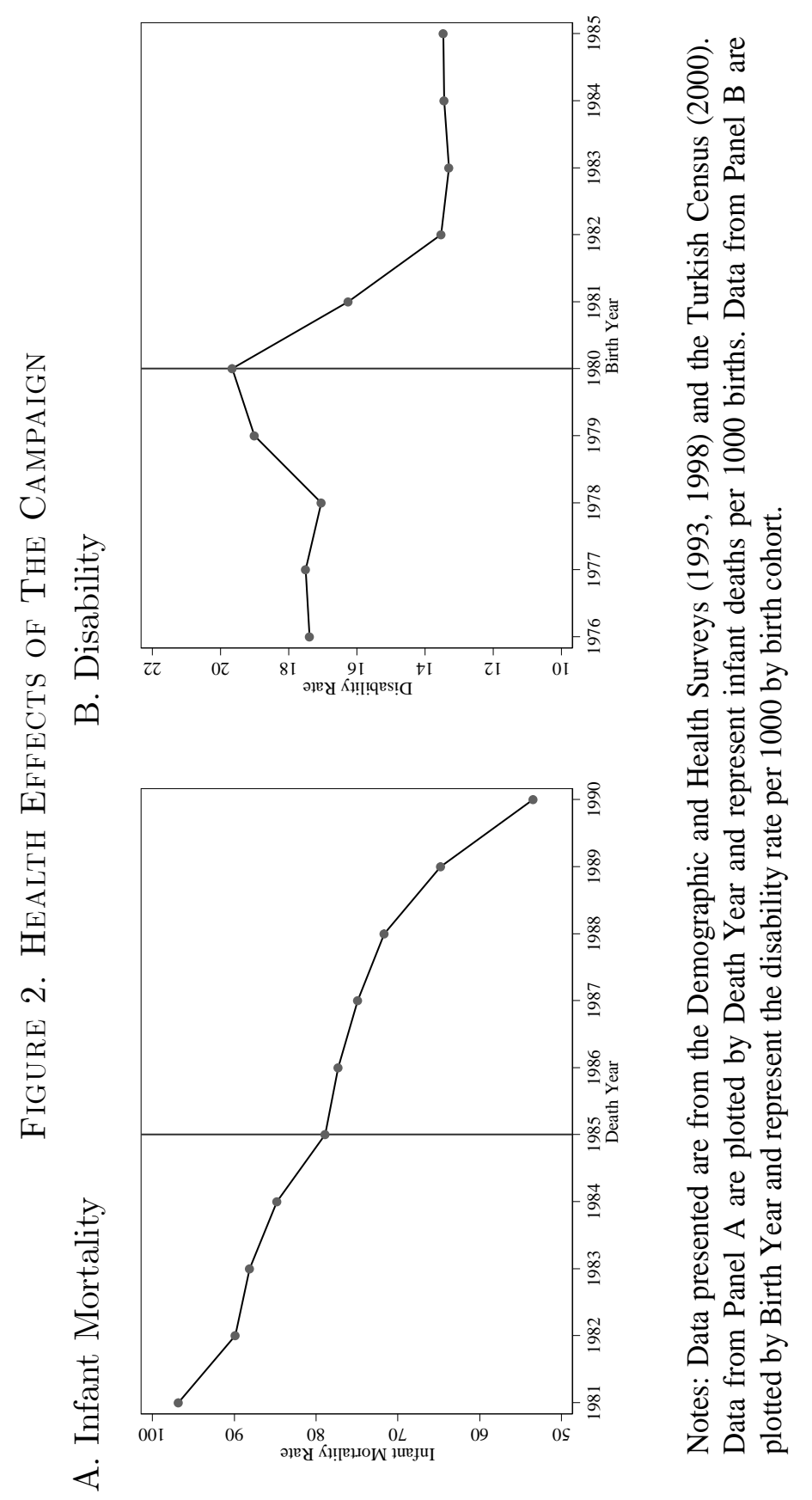




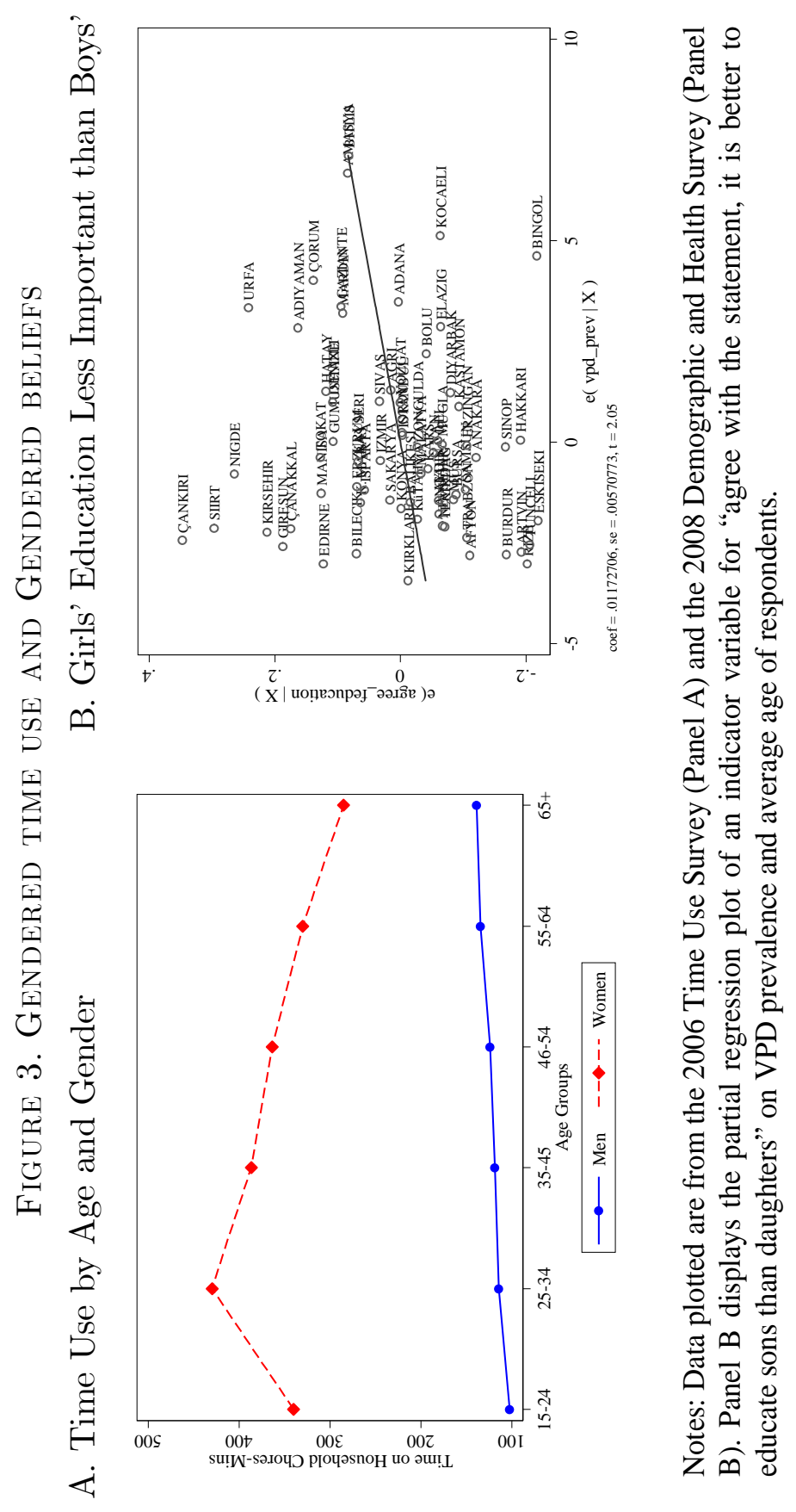




\subsection{Gender Norms in Turkey}

This section seeks to provide context for the gender norms that existed and upon which the immunization campaign was superimposed to motivate the hypothesis that girls might have benefitted more in response to early child health interventions than boys. Patterns on time use by gender and beliefs about the relative benefits of educating girls are described.

\subsubsection{Time Use}

The first nationally representative time use survey in Turkey was performed in 2006. Although approximately 20 years after the intervention, the pattern produced below is relevant and was likely more pronounced at the time of the campaign. Figure 3 Panel A shows the time (in minutes) that are spent on household activities by age group and gender. The divergence in tasks begins early: young women 15 to 24 years old report spending much more time on household activities than their male peers. These results are similar when looking within households. A regression of time (in minutes) spent on household chores on gender and household fixed effects limited to never married individuals 15-24 years of age yields a coefficient of 169.19 significant at the $1 \%$ level. Within the same household, in 2006, girls spent almost three hours more on household activities than boys did on a typical day.

\subsubsection{Beliefs about Education}

Since the Kemalist Reforms, education was compulsory in Turkey and part of a larger strategy to reduce the influence of religious schools as well as develop a workforce for modernization. According to Berkes (1998, p. 466), "the constitutional provision that every Turkish citizen had the right to free primary education and the subsequent educational laws making secular education compulsory to the age of twelve were active deterrents to the opening of religious schools in competition with the primary schools administered by the Ministry of Education." Despite this law, there may be parental preferences regarding child education by gender. The Demographic and Health Survey in 2008 asked women whether they agreed with this statement: "It is better to educate sons than daughters." I limit the sample to mothers born on or before 1965, so as to recreate the views of the population that would have had young kids at the time of the campaign. Caution should be used when interpreting the results given concerns about survival bias, demand bias and opinions shifting over time. There is heterogeneity in the proportion of mothers that admit to agreeing with this statement, close to zero in some provinces, and almost two-fifths in others. Figure 3 Panel $\mathrm{B}$ shows a positive correlation between where this view is more openly expressed and the pre-campaign VPD prevalence, conditional on age. Together, these graphs provide support for the notion that girls were often tasked with childcare roles (or household chores when a mother is preoccupied with a sick child) and that girls' education was viewed as less important than boys', particularly in areas where the campaign should have had the greatest 
impact.

\section{Model of Intrahousehold Time Allocation in the Pres- ence of Early Childhood Illness}

In this section, I develop a simple model which seeks to interpret the empirical findings. Building on the work of Jere Behrman and colleagues, parents seek to maximize a parental welfare function that gives equal weight to each child and is additively separable in a vector of expected earnings $(\mathbf{E})$ for each of their $i$ children. Following Behrman, Pollak, and Taubman (1982) I ignore the sequential nature of the decision-making and view allocation as a oneperiod problem taking the number of children as a given.

To focus attention on the salient features of the applied work, I assume there are three children per household: an older schoolage boy and girl sibling and an under-five younger child. The expected earnings of each $i$ child is a function of their time in school $S$ (if ageeligible) and an early childhood health investment, $H: E_{i}=E\left(S_{i}, H_{i}\right)$. Health of young children are determined by their endowment at birth, $e$, which is complemented by investments of domestic time. For older schoolage children, the stock of health-related time investments when the child was under-five is fixed at $H_{o} \sqrt{13}$ For any child $i$ the expected earnings is therefore: $E_{i}=p\left(S_{i}, H_{i}\right) w_{s}$ where $p(\cdot)$ is the probability of earning the skilled wage and is strictly concave and monotonically increasing in both arguments. I assume the skilled wage is higher for males than female, $w_{s}^{b}>w_{s}^{g}$, which is in line with the data and determined by equilibrium in the labor market 14 I also assume that separate spheres start early, so that the outside option for the older girls' time, were she not in school, would be to perform domestic duties worth price of $w_{d}$ whereas the older boy would work in agriculture for $w_{a}$. This division of labor could be due to a comparative advantage males have in "brawn" (Pitt, Rosenzweig, and Hassan, 2012) or the historical use of the plow (Alesina, Giuliano, and Nunn, 2013). ${ }^{15}$ The parents' choose schooling and child health investment to optimize

\footnotetext{
${ }^{13}$ Complementarities between genetic endowments, early child investments and schooling are clearly important (Cunha and Heckman, 2007). However, the model does not need to assume that genetic endowments differ between the sexes or that parents place a higher welfare weight on boys versus girls to obtain the gender gap in schooling (equation (1)). Behrman (1997) calls this form of parental preference "equal concern."

${ }^{14}$ Ilkkaracan and Selim (2007) review the literature on the wage gap in Turkey and note that estimates vary widely, but data using official statistics show that women on average earn $60 \%$ of men according to the hourly wage rate based on 1987 data.

A simpler model whereby the labor market return to boys' education is higher than girls' predicts girls should be preferentially pulled out of school for any household income shock; whereas the model presented below distinguishes between agriculture and domestic shocks and assesses their varying effect on the gender gap in education. Empirical evidence suggests the type of shock does matter. Jensen (2000) shows that rainfall deviations have a larger (negative) effect on boys' education than girls in affected areas.

${ }^{15}$ The model is a simplification, since girls often perform agricultural work as well, though all that is needed is relative specialization by girls and boys from an early stage. This assumption lines up with the data on gender and child labor in agriculture: boys are 37 percentage points more likely to be working in agriculture than girls, where girls are more likely to work in the service sector as well as "performing
} 
future earnings subject to the relevant constraints:

$$
\begin{aligned}
\max _{S_{b} S_{g}, H_{y}} U\left(E_{i} \mid v\right) & =\left[p\left(S_{g}, H_{0}\right) w_{s}^{g}\right]+\left[p\left(S_{b}, H_{0}\right) w_{s}^{b}\right]+\left[p\left(H_{y}\right) w_{s}^{y}\right] \\
\text { s.t. } Y+w_{d} D_{g}+w_{a} A_{b} & =p_{s}\left(S_{g}+S_{b}\right)+p_{d} H_{y} \\
T_{g} & =D_{g}+S_{g}, T_{b}=A_{b}+S_{b}
\end{aligned}
$$

where $g, b, m, y$ index girl, boy, mother, and young child, respectively, $T, S, D, A, H$ indicate total, schooling, domestic, agricultural and health investment time, $w, p$ indicate prices and $v$ indicates whether or not the child is ill. If the young child is healthy $(v=1)$, the mother inelastically supplies all her labor for chores which safeguard child health and such inputs are sufficient. However, if the young child is ill $(v=0)$, the mother's supply of time is not sufficient so that, $H_{y}=v e D_{m}+(1-v) e\left(D_{m}+D_{g}\right)$.

Calculating full income and maximizing when $v=1$ yields the following equilibrium condition which characterizes the gender gap in schooling:

$$
p^{\prime}\left(S_{b}\right)=\frac{w_{s}^{g}}{w_{s}^{b}} \frac{w_{a}+p_{s}}{w_{d}+p_{s}} p^{\prime}\left(S_{g}\right)
$$

The first term on the right hand side of this equation represents gender-based labor market discrimination and the second term reflects within household discrimination which readies girls for domestic work and boys for manual labor. Boys are predicted to be allocated more time in school than girls as long as the ratio of agriculture and domestic prices is less than that for skilled labor: $\frac{w_{a}+p_{s}}{w_{d}+p_{s}}<\frac{w_{b}}{w_{g}} \Rightarrow p^{\prime}\left(S_{g}^{*}\right)>p^{\prime}\left(S_{b}^{*}\right) \Leftrightarrow S_{g}^{*}<S_{b}^{*}$. Positive shocks to the local price for domestic work (due, for example, to increased demand in the setting of inelastic supply) widen the education gap whereas agricultural shocks reduce it. ${ }^{16}$

If $v=0$, the first order condition with respect to the education of the older boy is unchanged and reflects the trade-off between prices for agriculture and skill. However, for older sisters the marginal probability of schooling now must equal the ratio of shadow wages plus a term in the younger sibling: $e w_{s}^{y} p^{\prime}\left(H_{y}\right)$. Thus schooling for girl children will be smaller when the young child is ill than if he is healthy widening the education gender gap 17 Note that the gender of the younger child matters as well - since younger brothers have a higher skilled labor market return, this further reduces equilibrium girl education. ${ }^{18}$

household chores within their own homes (International Labor Organization, 2016)."

${ }^{16}$ In the United Nations Report "Legislative Reform on Child Domestic Labour: A Gender Analysis" it is estimated that 350 million children ages 5-17 are engaged in work, a large percentage in domestic service (UNICEF, 2008, page i). In addition, "Traditional gender roles have contributed to the assumption that women and girls make ideal domestic workers because they are subservient and meek. They are also expected to be well skilled at care giving, child rearing and house keeping, all activities considered to be an extension of the woman's natural role (UNICEF, 2008, page 3)." See work by Goldin (1992) for a discussion of the constancy in gender distinctions in the historical United States labor market.

${ }^{17}$ Since $p \prime\left(S_{b}\right)=\frac{w_{s}^{g}}{w_{s}^{b}} \frac{\lambda\left(w_{a}+p_{s}\right)}{e w_{s}^{y} p^{\prime}\left(H_{y}\right)+\lambda\left(p_{s}+w_{d}\right)} p^{\prime}\left(S_{g}\right)<\frac{w_{s}^{g}}{w_{s}^{b}} \frac{\lambda\left(w_{a}+p_{s}\right)}{\lambda\left(p_{s}+w_{d}\right)} p^{\prime}\left(S_{g}\right)$

${ }^{18}$ See Appendix Figure B5 for evidence consistent with this effect. 


\section{Empirical Strategy and Data Construction}

To identify the effect of the campaign on health and human capital, I employ a differencein-differences (DD) estimator, using the approach described by Card (1992). I use available health statistics to develop a baseline measure of the prevalence of vaccine prevalence illness at the local geographic level. The national immunization campaign then provides a treatment effect that varies depending on how high the burden of disease is prior to its introduction. Cohorts between 0 to 60 months at the time of the campaign (whose year of birth is between 1980 and 1986) are affected while cohorts born before that time are not directly affected as in a traditional DD framework ${ }^{19}$ The grouped version of this estimator is as follows:

$$
\text { Outcome }_{p t}=\alpha+\beta\left(V P D_{p} I_{t}^{\text {post }}\right)+\gamma I_{t}^{\text {post }}+\rho V P D_{p}+\mathbf{X}_{p t}^{\prime} \Gamma+\varepsilon_{p t}
$$

where $p$ denotes province and $t$ denotes time. Equation (2) is used because demographic variables such as child mortality are only calculable at the provincial level. $\mathbf{X}_{p t}$ includes average maternal literacy, family size, log number of hospitals per capita, professional status of father, and fraction female. I next turn to an estimating equation which analyzes outcomes at the individual level, $i$. This specification allows for the inclusion of individual level controls to increase precision and time-varying covariates measured at the province level that may be a source of omitted variable bias (Angrist and Pischke, 2009) and permits an investigation of differential response by gender. The estimating equation is:

$$
\text { Outcome }_{i p t}=\alpha+\beta\left(V P D_{p} I_{t}^{\text {post }}\right)+\sum_{c} \gamma_{c} I_{p}^{c}+\sum_{j} \rho_{j} I_{t}^{j}++\theta I_{i}^{g i r l}+\mathbf{X}_{i p t}^{\prime} \Gamma+\varepsilon_{i p t}
$$

where $I_{p}^{c} I_{t}^{j}$ and $I_{i}^{g i r l}$ represent indicator variables for province, birth cohort and gender, respectively. $\beta$ is the difference-in-differences estimate. $\mathbf{X}_{i p t}$ is a column vector of covariates that vary at the individual, household or birth province level and have been shown to influence children's health and human capital, such as maternal literacy, family size, father's occupation, age rank and sex composition of siblings ${ }^{20}$ I assess for a gendered impact of the

\footnotetext{
${ }^{19}$ The peak in disabled for the 1980 cohort (Panel B of Figure 2) could be consistent with age heaping. In the main analysis, the estimates use repeated cross sections and do not include 1980 .

${ }^{20}$ Families with (more) girls might be larger if parents follow a son-biased stopping rule (see Clark (2000) and Barcellos, Carvalho, and Lleras-Muney (2014)). Appendix Figure B6 suggests that such a rule may have been followed in Turkey in 1985. I include family size and sex composition of siblings in all regressions. However, unlike other important recent work on sibling rivarly which uses sibling gender or composition as the main treatment variable, gender is considered a mitigating factor in the analysis herein. The distribution of vaccine preventable illness interacted with campaign rollout is used for identification. Furthermore, the spillover analysis focuses on the impact of younger siblings on older siblings, which typically has less selection bias than estimating the impact of older siblings on younger siblings due to endogenous fertility (see Appendix Tables V and VI versus III and IV in Vogl (2013)). Nevertheless, the interpretation of gender-specific heterogeneity in response to the campaign would be unclear if the treatment effect was correlated with either fertility or sex-selection in the data. I find no evidence of this (see Appendix Table B3). That treatment is orthogonal to pregnancy outcomes conditional on covariates is useful to document since there was a loosening of abortion legislation in Turkey in 1983. (I thank Onur Altindag for the comment).
} 
vaccination campaign on health and human capital outcomes by interacting each covariate in the individual-level specification with an indicator for girl. ${ }^{21}$ In this specification, $\beta_{1}$ represents the difference-in-differences estimate for boys and $\beta_{2}$ is the differential impact of the campaign for girls versus boys. $\beta_{1}+\beta_{2}$ is the estimate for girls: ${ }^{22}$

$$
\begin{aligned}
\text { Outcome }_{i p t}= & \alpha+\beta_{1}\left(V P D_{p} I_{t}^{\text {post }}\right)+\beta_{2}\left(V P D_{p} I_{t}^{\text {post }} I_{i}^{\text {girl }}\right)+\sum_{c} \gamma_{c} I_{p}^{c}+\sum_{j} \rho_{j} I_{t}^{j} \\
& +\mathbf{X}_{i p t}^{\prime} \Gamma+\left(I_{i}^{\text {girl }} \mathbf{X}_{i p t}^{\prime}\right) \Psi+\sum_{c} \gamma_{c}^{\text {girl }}\left(I_{i}^{\text {girl }} I_{p}^{c}\right)+\sum_{j} \omega_{j}^{\text {girl }}\left(I_{i}^{\text {girl }} I_{t}^{j}\right)+\varepsilon_{i p t} .
\end{aligned}
$$

The inclusion of province of birth fixed effects absorb differences between provinces that might jointly determine a high baseline VPD prevalence and the accumulation of human capital. The individual level regressions include cohort fixed effects to control for any other national policies or events that would affect human capital outcomes in a specific year for children of a given age. The use of province of birth to assign treatment reduces concern about endogenous migration.

To assess for spillover effects of early child health on older siblings, equation (3) is modified by replacing $I_{t}^{\text {post }}$ with $I_{t}^{\text {postspillover }}$ with the latter equal to one in census year 1990 for the cohort immediately older than the age-eligible population and zero for the same age-range in 1985. The sample includes children of household heads who were 11 to 14 years of age at the time of the 1985 and 1990 census and had younger siblings in the household. This age range is ideal since this group is young enough to still be residing with younger siblings who were targets of the campaign (enabling me to identify those indirectly affected) yet old enough to be ineligible for the campaign themselves. Note that the design matrix for the spillover analysis also includes age rank (birth order for those children that are in the household). In addition, enrollment statistics at the province level were gathered from the Turkish Statistical Institute (1982) and are described in section 5.

The estimation strategy compares health and human capital outcomes among individuals born in high versus low prevalence VPD provinces before and after the initiation of the immunization campaign. In order for the underlying variation in vaccine preventable illnesses to be useful as a natural experiment, it must be the case that the program had more of an impact in places where the prevalence of disease was higher. Reports immediately after the campaign support this idea: "The increases in vaccine percentages that the campaign has made possible, have been higher in rural areas and in regions where the percentages were lower before" (Tunçbilek, E et al., 1986, page 36). This is reflected in the near total

\footnotetext{
${ }^{21}$ Adding occupation of father and mother's literacy reduces my sample since some older children move out of the household. Including these parental characteristics allows a more direct comparision with the coefficients for the spillover effects in Table 7. Specifications that do not include parental characteristics can be found in Table 6 columns (7) and (8).

${ }^{22}$ Pooled models produce the same coefficients as separate regressions but are more efficient assuming the variance of the residuals is the same between sexes (Franzese and Kam, 2007).
} 
interruption of the targeted diseases in the years immediately following the campaign (Figure 4 Panel A).

\section{Figure 4. First Stage and Reduced Form}

A. "First Stage"

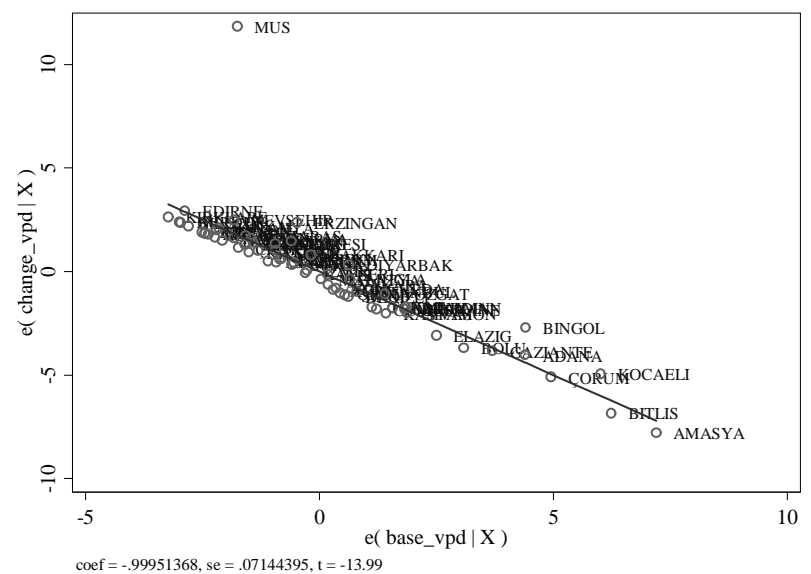

B. "Reduced Form"

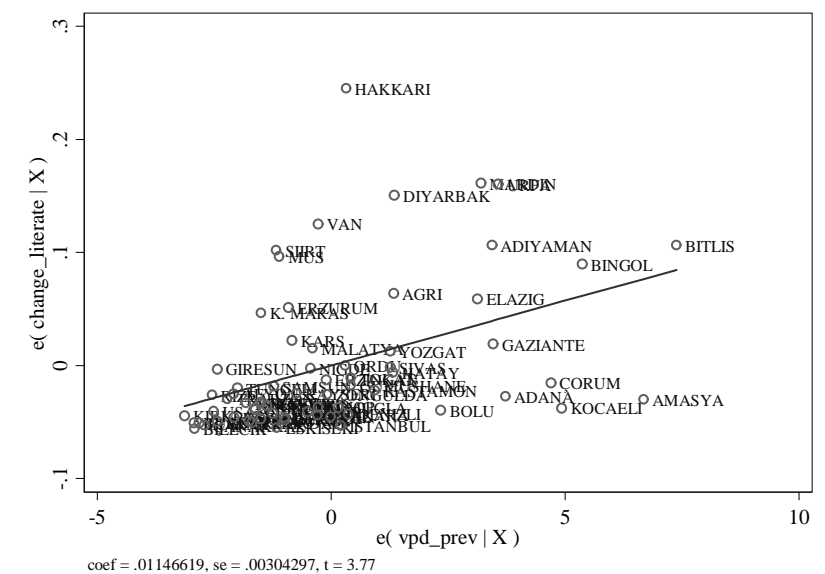

Notes: Panel A data are taken from Ölüm Istatistikleri and plots the relationship between the difference in VPD prevalence by province between the years 1990 and 1986 on the $y$-axis and the precampaign VPD prevalence in 1985 on the $\mathrm{x}$-axis. The one outlier is Mus, which had measles deaths in 1988 and 1989. For all other provinces, vaccine preventable illnesses essentially dropped to 0 after the campaign. Data from Panel B are from Turkish Censuses and plot the change in the proportion of the sample that is literate on the $y$-axis and the pre-campaign VPD prevalence on the $\mathrm{x}$-axis. The Census samples include individuals 15-19 years of age and post-campaign is defined as those born between 1980 and 1986 .

\subsection{Constructing Disease Prevalence}

To create a measure of prevalence of vaccine preventable diseases prior to the rollout of the campaign, I use the Turkish Mortality Statistics from 1977 to 1985 (Ölüm Istatistikleri). These data are collected annually and include number, cause and age of death at the province level. Using multiple years smooths out the epidemic nature of vaccine preventable illnesses: $\overline{V P D ~ d e a t h s}_{p}=\frac{1}{9} \sum_{y=1977}^{y=1985} V P D$ death $s_{p}^{y}$.

One feature of statistics from low and middle-income countries is the underreporting of vital events to local authorities, particularly in rural areas. Although vital events may be underreported, population counts, enumerated by the federal census, are generally not as poorly measured. Since incidence and prevalence rates are normalized by population, the bias introduced by underreporting of vital events is exacerbated by the use of a federal source for the denominator and a local source for the numerator when attempting to construct a meaningful epidemiologic or demographic measure ${ }^{23}$ To address the problem of nonrandom

\footnotetext{
${ }^{23}$ Poorly recorded vital statistics are also problematic if using disease or death counts on the left-hand side, even with fixed effects for province, since reporting errors can change over time in ways that are correlated with health interventions or policies.
} 
underreporting of vital events in the administrative data, I exploit a unique question in the 1985 Turkish census to construct a correction factor $(C F)$. The 1985 enumerators asked women whether they had given birth in the last 12 months and whether that baby had survived ${ }^{24}$ Assuming that are no systematic differences between underreporting of infant deaths and deaths from vaccine preventable disease, this ratio can then be used to correct for underreporting in rural areas: $\frac{\text { Infant Deaths } s_{p, 1985}^{\text {census }}}{\text { Infant Deaths } s_{p, 1985}^{\text {stiskleri }}}=C F_{p, 1985}$. Validation of this approach can be found in Appendix Figures B3 and B4, which show the correlation between the corrected vital statistics and health indicators from various other sources is much better than the uncorrected version.

The next step in constructing the prevalence of vaccine preventable disease from deaths is to use information on the case fatality rate $(C F R)$. The $C F R$ is the number of deaths divided by the number of cases of the disease, and can be used to scale up fatalities to represent infections at a particular point in time. One complicating feature is that the $C F R$ varies across illnesses and age groups. Since the majority of deaths recorded (81\%) are from measles, I focus on literature estimating $C F R$ for that disease. In a recent review by Wolfson, Grais, Luquero, Birmingham, and Strebel (2009) the median $C F R$ for measles is 16.45 for children 0 to 11 months and 2.24 for those 48 to 59 months of age. Thus, I use the $C F R$ specific to infants and scale the at risk population accordingly. Prevalence at the province level is the number of cases divided by the infant population. A map of VPD prevalence deciles across Turkey prior to the campaign is shown in Figure 5 below.

\section{Figure 5. Map of Pre-CAmpaign VPD Prevalence (Deciles)}

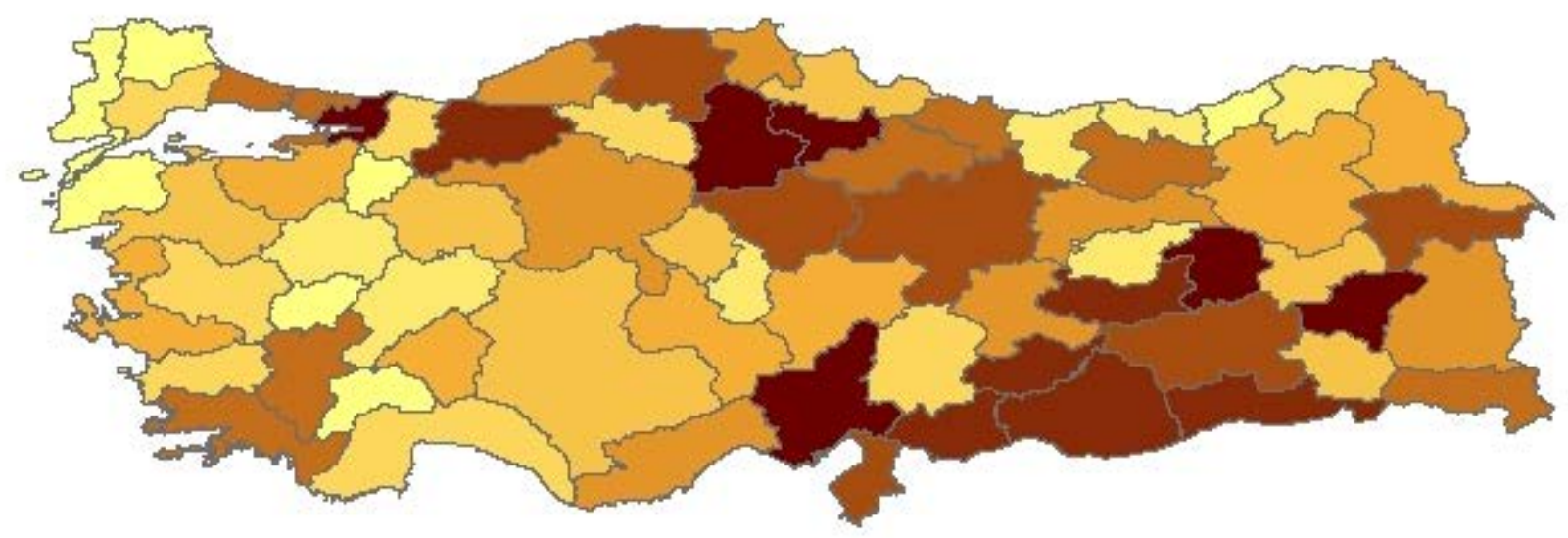

Notes: Map of deciles of VPD prevalence in the pre-campaign period for 67 provinces circa 1985. See text for details of VPD construction. Darker shades indicate higher prevalence.

Micro-level data on human capital outcomes and other household level controls come from the 5\% Turkish census sample provided by Integrated Public Use Micro Sample (IPUMS)

\footnotetext{
${ }^{24}$ More often the census question asks about the number of children ever born and the number of children that have survived.
} 
and the Turkish Statistical Institute (Minnesota Population Center, 2017). Census data are available for the years 1985, 1990 and 2000 and include data on literacy, educational attainment (less than primary, primary, secondary and university completed) and disability. To supplement these data, I also include data on years of schooling from the Demographic and Health Surveys (DHS) (ICF International, 2003, 1998, 1993) and data on school enrollment by gender from the Turkish Government. I merge individual observations from the censuses to the pre-campaign VPD prevalence. Provincial infant and child mortality rates are constructed from individual birth histories collected by the DHS. Time-varying provincial level data on healthcare access including number of hospitals are from the Turkish Statistical Abstract (Türkiye İstatistik Yilliği) and are also included (TurkStat, 1983, 1989).

The age-eligible sample in the main analysis includes individuals between 15 and 19 years old across two waves of census data, 1985 and 2000 ${ }^{25}$ Any individual younger than 15 in 2000 would have been subject to a major education reform in Turkey and must be excluded ${ }^{26}$ Furthermore, vaccination continued (though at a diminished level) post-campaign potentially affecting younger cohorts. Disability is not available in the 1990 census. I restrict the analysis to children who are still living in their birth province to reduce measurement error (e.g. not knowing precisely when the child moved) associated with treatment assignment for the main analysis and make the same restriction for older siblings in the spillover analysis ${ }^{27}$ Summary statistics are provided in Appendix Table B1 28

\section{Results}

\subsection{Effects of the Campaign}

The results of equation (2) are presented in Table 2. Consistent with Figure 2, there are no appreciable effects on the vaccination campaign on child or infant mortality in columns (4) and (5) ${ }^{29}$ However, I find statistically significant gains for both disability and human

\footnotetext{
${ }^{25}$ Given the age-dependence of human capital accumulation, the analysis centers on children who are of the same age and uses repeated cross sections from 1985 and 2000.

${ }^{26}$ According to Kirdar, Tayfur, and Koç (2011, page 11): "The new compulsory schooling system affected children who started school at or after September 1993, we assume that children who were born in 1986 or later were bound by the policy." Note that the youngest child in my sample is born in 1985 .

${ }^{27}$ For the spillover analysis, I assume that if older children are still living in their birth province then the household hasn't moved. This avoids having different younger children born in different provinces and introducing measurement error by choosing one of the younger children's birth provinces to assign VPD prevalence.

${ }^{28}$ The provinces included in the analysis are the 67 unique provinces that can be followed over the entirety of the study period. In Appendix Table B2 columns (11) and (12), I collapse the data to 61 mega - provinces. This collapse attempts to account for cleavages and combinations between provinces over time, but introduces additional measurement error into the baseline VPD estimates. The results are comparable to Table 5 columns (1) and (4).

${ }^{29}$ Bloom, Canning, and Shenoy $(2012)$ investigated the impact of vaccinations on human capital of treated children in the Phillipines and find effects on education but not height.
} 
capital accumulation at this level of aggregation (columns (1) to (3)) ${ }^{30}$ The coefficient on VPD prevalence is insignificant except for the outcome of disability which lends support to the identifying assumption that, in the absence of the campaign, groups with high and low vaccine preventable illness would have experienced similar changes in the outcome variables. Based on the low overall fatality rate from vaccine preventable disease in Turkey at this time, in retrospect, the results on mortality may not appear particularly surprising.

Table 2. Effects of The Campaign - Province-Level

\begin{tabular}{lccccc}
\hline Dependent Variable & Disabled & Literate & $\begin{array}{c}\text { Educational } \\
\text { Attainment }\end{array}$ & $\begin{array}{c}\text { Infant } \\
\text { Mortality } \\
\text { Rate }\end{array}$ & $\begin{array}{c}\text { Child } \\
\text { Mortality } \\
\text { Rate }\end{array}$ \\
\hline & $(1)$ & $(2)$ & $(3)$ & $(4)$ & $(5)$ \\
\hline VPD Prevalence *Post & $-0.0003^{*}$ & $0.0104^{* *}$ & $0.0172^{*}$ & 1.1241 & -0.7711 \\
& $(0.0001)$ & $(0.0049)$ & $(0.0100)$ & $(6.9431)$ & $(4.2981)$ \\
Post & $0.0067^{* * *}$ & $-0.0394 * *$ & -0.0324 & -6.8676 & -8.4341 \\
& $(0.0009)$ & $(0.0173)$ & $(0.0360)$ & $(23.1461)$ & $(18.5060)$ \\
VPD Prevalence & $0.0003^{* *}$ & -0.0049 & -0.0076 & 0.6822 & 0.4430 \\
& $(0.0002)$ & $(0.0046)$ & $(0.0099)$ & $(3.9186)$ & $(3.3148)$ \\
Observations & & & & & \\
R-squared & 134 & 134 & 134 & 130 & 130 \\
Number Clusters & 0.4695 & 0.7036 & 0.8081 & 0.1856 & 0.2172 \\
\hline
\end{tabular}

Notes: OLS estimates of equation (2). Child mortality constructed using birth history data from the Demographic and Health Surveys (1993 and 1998). Literacy, disability, and educational attainment come from the Turkish Census. In addition to the variables shown (VPD prevalence, post and the interaction), the regression also controls for fraction female, average maternal literacy, family size, paternal occupational status, and log of total hospitals per capita. Regressions are weighted by the relevant cell size in columns (1) to (3). Siirt and Tunceli were not included as provinces of birth for women included in the Demographic and Health surveys. Standard errors clustered at the province level.

$* * * * * *$ represent significance at the 10,5 and 1 percent level, respectively.

\subsection{Threats to Identification}

In order for the estimates to be interpreted as causal effects, it must be that VPD prevalence in the pre-campaign period is as good as randomly assigned conditional on covariates and places of varying pre-campaign VPD prevalence must be on parallel trends. Table 3 addresses the first claim. Column (1) presents summary statistics for the age-eligible province level sample used in Table 2. In column (2) I regress each covariate on VPD prevalence alone

\footnotetext{
${ }^{30}$ Disability has a low mean (approximately $1 \%$ of the sample) in the census. It is important to note that, like the case fatality rate, disability from vaccine preventable illnesses is much lower than their incidence and overall morbidity. There is precedent for using disability in the census to measure the impact of infectious disease at the population level (Almond, 2006).
} 
and in column (3) I include all other covariates in the analysis. Although pre-campaign VPD prevalence is positively associated with less human capital and larger families, once conditioning on covariates, VPD prevalence fails to predict most of the variables in the precampaign period, except for disability (the implicit first stage) and a binary variable for whether the father is in a skilled occupation.

Table 3. Summary Statistics and Balance

\begin{tabular}{lccc}
\hline \multicolumn{3}{c}{ Province Characteristics in 1985 by VPD Prevalence } \\
\hline \multirow{2}{*}{ Variable } & \multirow{2}{*}{ All } & \multicolumn{2}{c}{ VPD Prevalence } \\
\cline { 3 - 4 } & & without controls & with controls \\
\hline Disabled & 0.0120 & $0.0005^{* * *}$ & $0.0004^{* *}$ \\
Literate & {$[0.003]$} & $(0.0002)$ & $(0.0002)$ \\
& 0.897 & $-0.0192^{* *}$ & -0.0002 \\
Educational Attainment & {$[0.128]$} & $(0.0077)$ & $(0.0043)$ \\
& 1.816 & $-0.0437^{* *}$ & -0.0007 \\
Mom Literate & {$[0.289]$} & $(0.0173)$ & $(0.0093)$ \\
& 0.438 & $-0.0336^{* * *}$ & -0.0072 \\
Log Hospitals per Capita & {$[0.191]$} & $(0.0093)$ & $(0.0049)$ \\
& -11.31 & $-0.0472^{* *}$ & -0.0134 \\
Father's Occupation & {$[0.402]$} & $(0.0186)$ & $(0.0238)$ \\
Family Size & 0.802 & -0.0035 & $-0.0104 * *$ \\
& {$[0.072]$} & $(0.0035)$ & $(0.0045)$ \\
Fraction Female & 6.095 & $0.1656^{* * *}$ & 0.0051 \\
& {$[0.997]$} & $(0.0437)$ & $(0.0256)$ \\
Number Provinces & 0.516 & -0.0019 & -0.0015 \\
& {$[0.0271]$} & $(0.0012)$ & $(0.0014)$ \\
& 6 & 67 & 67 \\
\hline
\end{tabular}

Notes: Column (1) reports average values for the 67 provinces with standard deviation in brackets. Columns (2) and (3) report coefficients from a single regression of indicated province characteristics in the pre-campaign period on VPD prevalence. Column (3) adds controls described in Table 2. Robust standard errors are reported in parentheses.

$* * * * * *$ represent significance at the 10,5 and 1 percent level, respectively.

To address the concern about differential trends between places with more versus less disease at baseline, I perform a falsification test where I estimate equation (2) substituting the period 1961-1965 as the pre-period of analysis and 1966 to 1970 as the post-period. (Note that I am limited in the use of adjacent cohorts due to spillover effects to older siblings as demonstrated below). The results are shown in Table 4 - the interaction of placebo post and VPD prevalence is no longer a significant predictor of morbidity or human capital. 
Table 4. Falsification Test-Province level

\begin{tabular}{lccc}
\hline \multicolumn{1}{c}{ Dependent Variable } & Disabled & Literate & $\begin{array}{c}\text { Educational } \\
\text { Attainment }\end{array}$ \\
\hline VPD Prevalence*Placebo Post & $(1)$ & $(2)$ & $(3)$ \\
& -0.0000 & 0.0012 & 0.0021 \\
Post & $-0.0004)$ & $(0.0012)$ & $(0.0033)$ \\
& $(0.0016)$ & $(0.0067)$ & $0.0842^{* * *}$ \\
VPD Prevalence & 0.0002 & 0.0010 & -0.0020 \\
& $(0.0003)$ & $(0.0015)$ & $(0.0048)$ \\
Observations & & & 134 \\
R-squared & 134 & 134 & 0.9313 \\
Number Clusters & 0.1771 & 0.9475 & 67 \\
\hline
\end{tabular}

Notes: OLS estimates of equation (2) estimated on individuals born between 1961 and 1970. Placebo post is an indicator variable equal to one if the year of birth is greater than or equal to 1966. Literacy, disability and educational attainment are from the Turkish Census. In addition to the variables shown (VPD prevalence, post and the interaction), the regression also controls for fraction female, average maternal literacy, family size, paternal occupational status, and log of total hospitals per capita. Regressions are weighted by the relevant cell size in columns (1) to (3). Standard errors clustered at the province level.

$* * * * * *$ represent significance at the 10,5 and 1 percent level, respectively.

I next turn to estimating the impact of the campaign using micro-level data from individuals. These specifications allows for the inclusion of time-varying provincial level variables which may be a source of omitted variable bias such as mother's literacy, father's occupational status, family size, gender, age rank and fraction girl siblings (LeVine and Rowe, 2009; Black and Devereux, 2011). Table 5 reports results for three outcomes: disabled, literate and educational attainment. Columns (1) (4) and (7) estimate equation (3). A one standard deviation increase of vaccine preventable illness in the pre-campaign period was associated with approximately a $5 \%$ decline in disability, a $3 \%$ increase in literacy and a $2 \%$ increase in educational attainment. The low overall mean of disability in the population (about 1\%) likely reflects under-reporting. If this under-reporting is worse in areas that were heavily impacted by the campaign, areas with high VPD prevalence at baseline, this would weaken my ability to detect an effect of the campaign.

Columns (2) (5) and (8) estimate equation (4) and formally test whether the marginal effect of the campaign differed for boys versus girls. For disability, the impact of the campaign for girls is indistinguishable of that for boys. Yet the marginal effect for girls is statistically significant when the outcome is literacy or education. How could boys have similar health gains but smaller human capital gains from the campaign? There are a few possibilities. For instance, discrimination or higher returns to boys in the labor market could create a 
differential health threshold to educate boys versus girls. Another possibility is that girls are benefitting from the campaign through an additional channel that is not related to improved own health. Put differently, the estimates below might reflect both direct and spillover effects for girls, but mostly direct health benefits for boys. Note that vaccination continued for children born after 1985, and therefore these individuals likely benefitted from having healthier younger children in their household - a hypothesis this paper is focused on and is examined in detail below ${ }^{31}$ Tentative support for such a possibility is provided by the gender-family size interactions: larger families have a much more negative impact on girls' human capital than boys'. Furthermore, for 15 to 19 year olds with few younger children in the household, the direct effects of the campaign are observed (columns (3) (6) and (9)) but the gender-specific effects are absent (e.g. $\beta_{1}$ is significant, but $\beta_{2}$ is not).

A series of robustness checks are performed in Table 6 and in the Appendix. First, Kurdish areas are dropped in columns (1) and (2). Although literacy is no longer statistically significant; the point estimate is comparable to baseline. In Appendix Table B2 one region is dropped at a time. The results are generally robust, except the results on literacy are weakened when dropping the entire Eastern region of the country (e.g. dropping 17 of 67 provinces). This region had the highest VPD prevalence and lowest literacy rates prior to the campaign. Second, I add birth province interacted with a linear trend for year of birth. Literacy retains significance and the expected sign, but disability flips signs and is no longer significant. Columns (5) and (6) adjust for mean reversion by interacting post with regional averages of the outcome variables calculated using the pre-period sample. The results are robust to controlling for mean reversion using this approach. Results are similar but not quantitatively significant when including province-level averages of the outcome from the pre-period interacted with post. The last two columns drop all parental controls increasing the sample size. Results for disability are no longer statistically significant but are similar in magnitude to the baseline; results for literacy are still significant.

\subsection{Spillovers to Older Siblings}

\subsubsection{Census Data}

I next turn to elucidating whether the intervention had an impact on older siblings of children age-eligible for the intervention by using equations (3) and (4) and replacing $I_{t}^{\text {post }}$ with $I_{t}^{\text {postspillover }}$ as described above. The results are reported in Table 7. Panel A reports OLS estimates for the outcome literate and Panel B reports the results for the outcome of educational attainment. I cannot test for spillover effects on disability since it was not reported in the 1990 census.

In column (1), the spillover difference-in-differences estimate is positive and significant. Moving to specification (4) in column (2), these results are driven by $\beta_{2}$, the additional

\footnotetext{
${ }^{31}$ Living in a household with vaccinated family members would also benefit young children's health.
} 
spillover effect for girls, since $\beta_{1}$ is small and not statistically significant. The differential spillover effect of the campaign on literacy for girls (0.0058) is significant at the $5 \%$ level. The total spillover effect for adolescent girls who were not age-eligible for the vaccination campaign is approximately $45 \%$ as large as the total effect for girls who were age-eligible for the health intervention. The results in Panel B display a similar pattern, with the spillover effect explaining much of the gender-specific age-eligible result.

The results imply the spillover benefits of young children's health on the human capital of older siblings in the household accrued exclusively to girls. To probe mechanisms which might explain such a pattern, I limit the analysis to a subsample of children whose mothers state they work outside the home. This widens this gender difference (column (3)) as does restricting to cotton-growing areas in column (4) of Panels A and $\mathrm{B}{ }^{32}$

Other researchers have pointed out the importance of grandmothers for girls' health. Duflo (2003) finds that the anthropometrics of girl grandchildren living with grandmothers newly eligible for pension funds in South Africa improve substantially, whereas boys' health does not respond. There is also anecdotal evidence that grandmothers assist mothers in rearing children and therefore may function as maternal substitutes. Motivated by this evidence, I compare the gender-specific spillover effect of the campaign in households with a grandmother (column (5)) or with an older sister (column (6)). When grandmothers or older sisters are present, the gender-specific spillover effects dissipate entirely. There is a genderneutral spillover effect when grandmothers are present and this is likely due to the fact that grandmothers are present in households which are on average much larger than household without grandmothers. In contrast to older sisters, when older brothers are present (column (7)), the magnitude of the gender-specific spillover effect increases. Column (8) is included as a placebo test. If there are no young children in the household, spillover effects should be absent. This prediction is largely borne out in the data. For literacy there is not a genderspecific spillover effect but a small (in magnitude) and marginally significant $\beta_{1}$ effect. For educational attainment, $\beta_{1}$ and $\beta_{2}$ are both small and insignificant. Taken together, these results lend support to the notion that older sisters benefitted from the campaign and the mechanism is via their time allocation shifting from domestic work to education.

\footnotetext{
${ }^{32}$ It is estimated that $80 \%$ of the workforce that is engaged in cotton harvesting in Turkey are women (International Trade Centre, 2011, p. 7).
} 


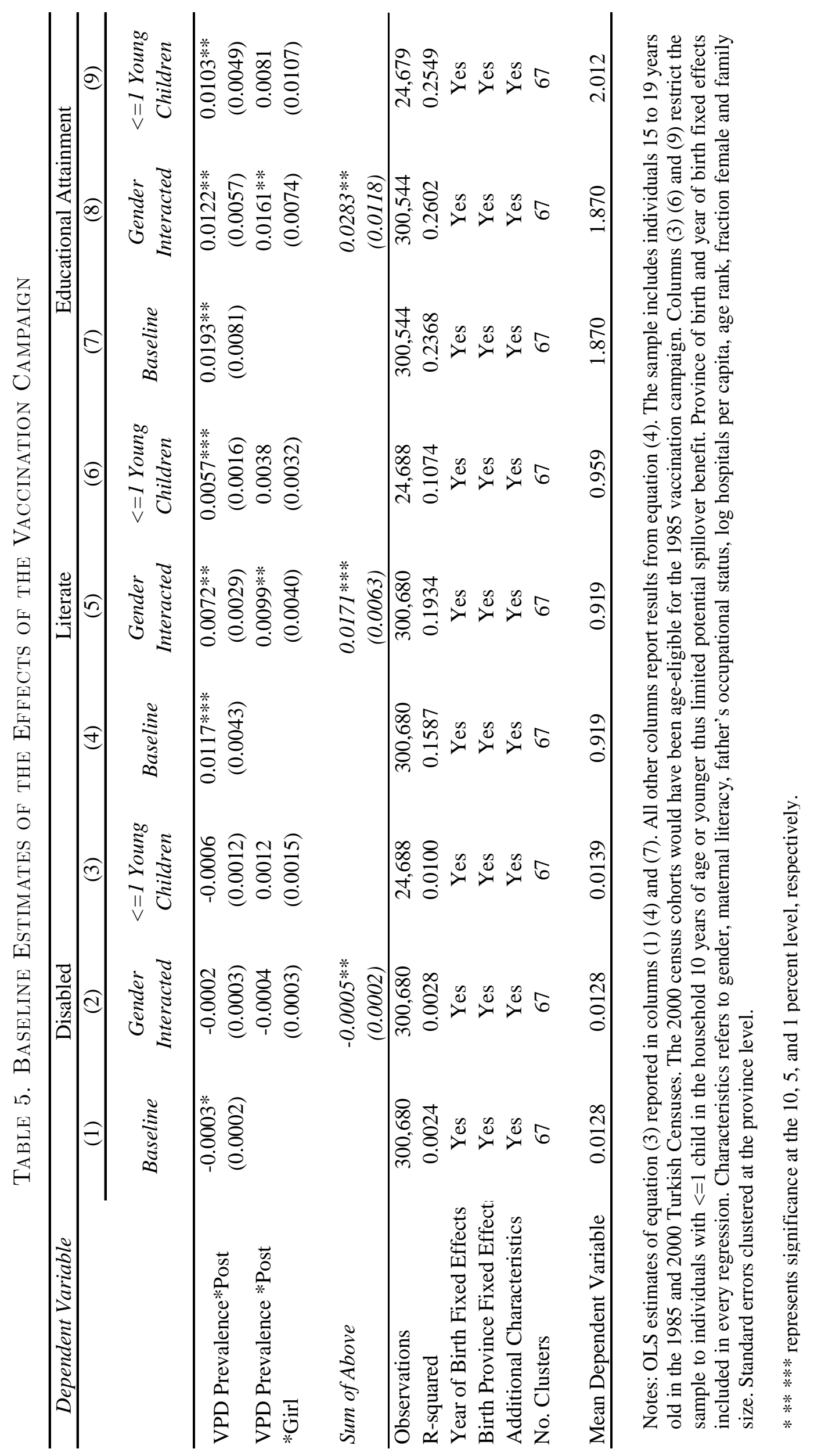




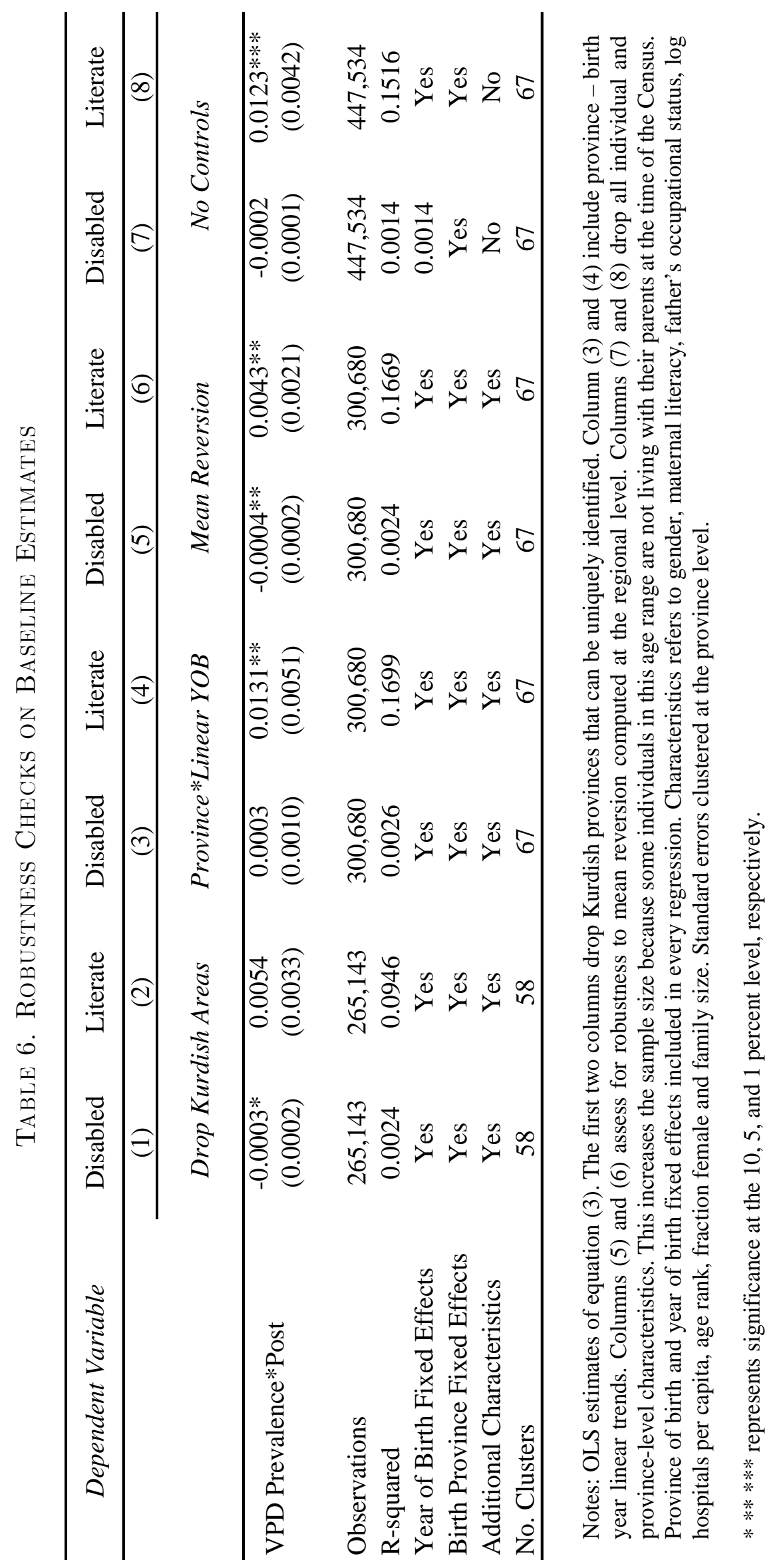




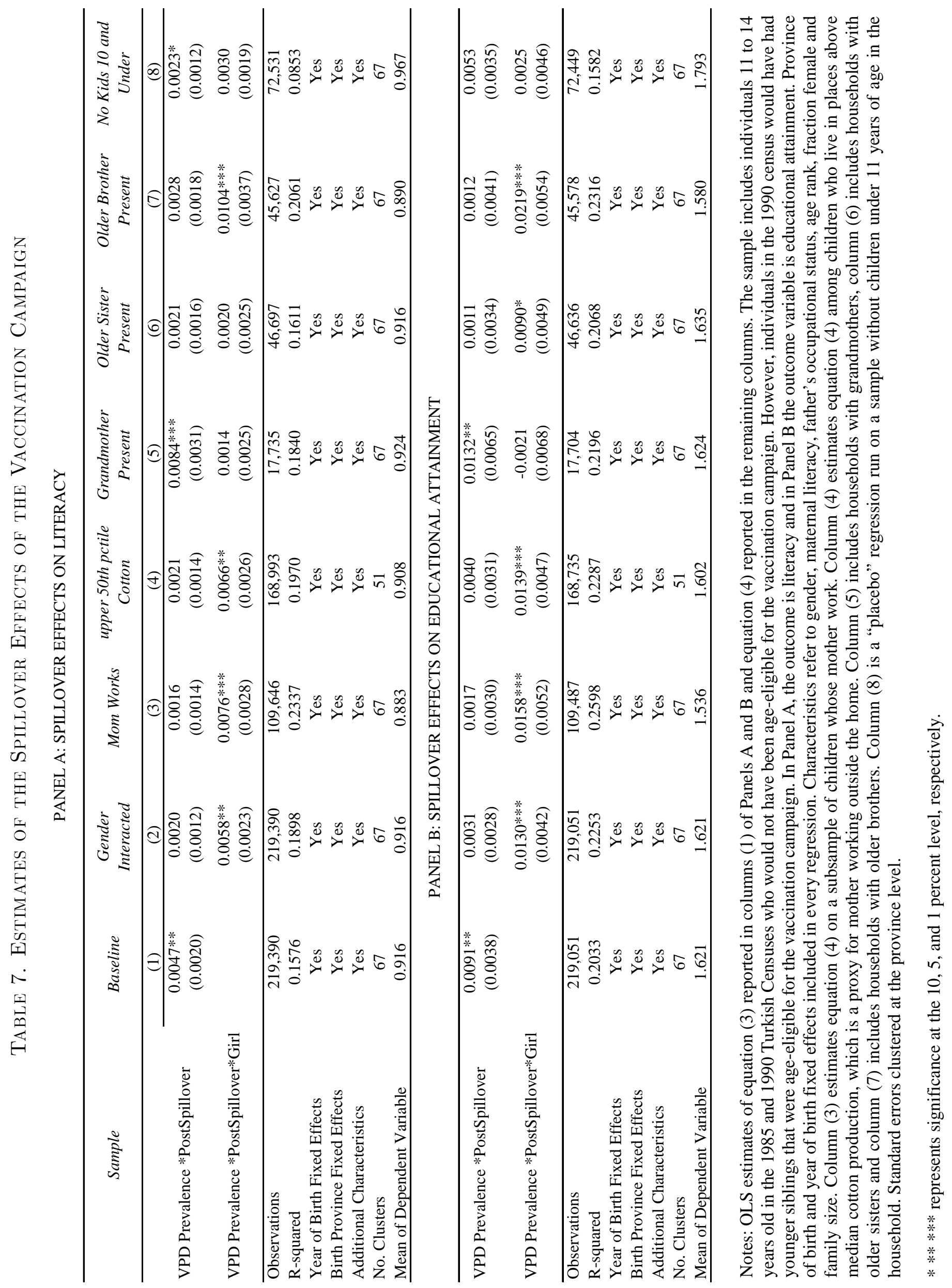




\section{Figure 6. Gendered Spillover Response by Number Children}

A. Older Sisters

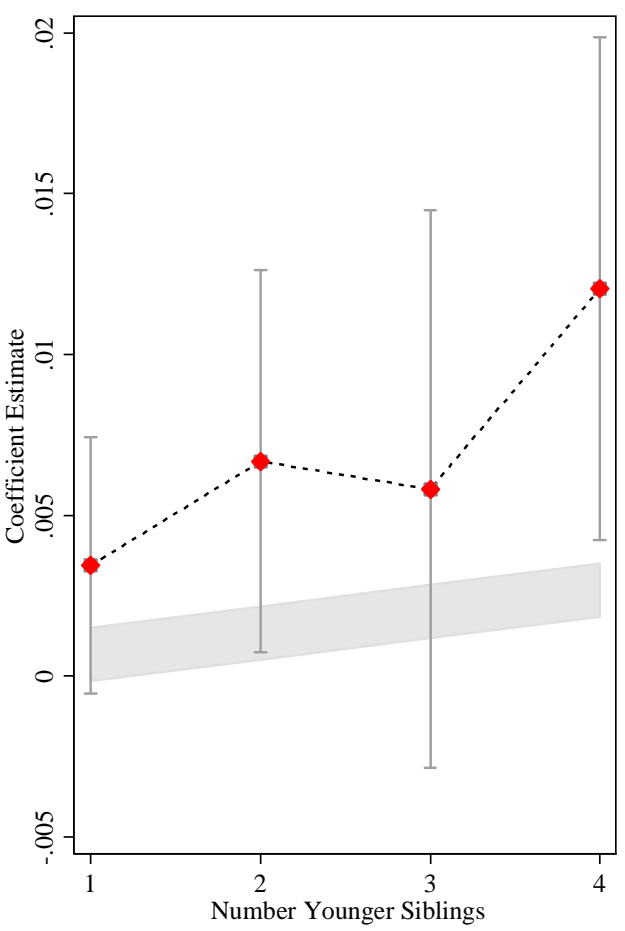

B. Older Brothers

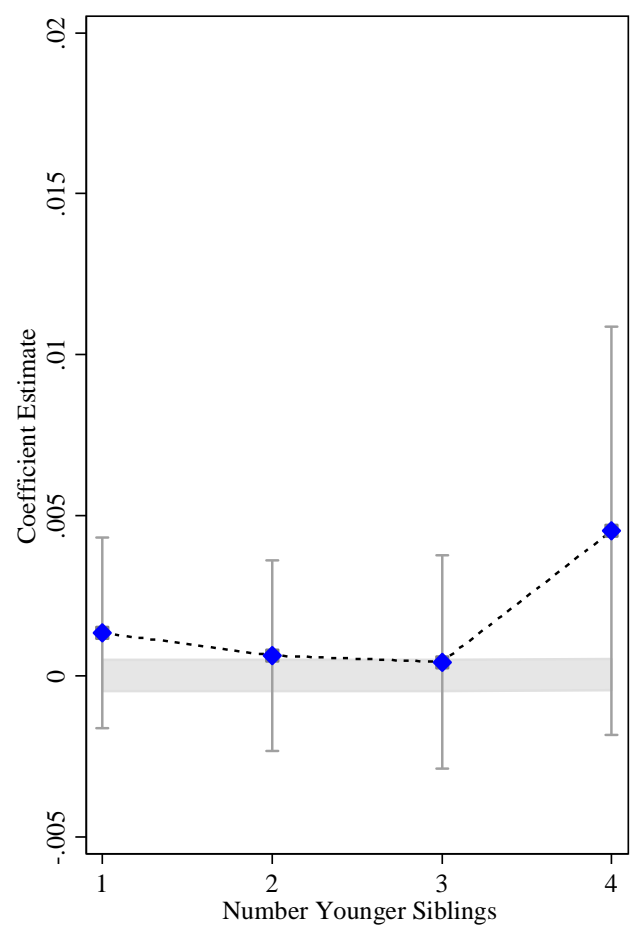

Notes: OLS estimates of equation (3) run separately by gender and by number of children 10 and under in the household. Figure represents the marginal spillover effect of the campaign for girls (Panel A) versus boys (Panel B). Plotted are the coefficients (points) and 95\% confidence interval from each gender/child combination. The shaded area represents the $95 \%$ confidence interval of a parametric specification with number of children ten and under interacted with the treatment variable, estimated separately by gender.

Figure 6 plots the marginal spillover effect of the campaign on girls versus boys by the number of siblings 10 years of age and under for the literacy outcome 33 The results demonstrate a pattern consistent with Figure 1 - namely, the benefits of mass dissemination of the vaccine technology were higher for girls than boys and this difference increased in the number of young, potentially treated children in the household. A linear estimation of the same pattern is shaded and superimposed on the figure.

\subsubsection{Evidence from Demographic and Health Surveys}

I supplement the spillover analysis using the household files from the DHS ${ }^{34}$ These data have number of years of education and harmonized education levels, which allows for an exploration of where in the years of schooling distribution the campaign may have had an

\footnotetext{
${ }^{33}$ This includes those directly vaccinated as part of the campaign (those 5-9 years old) as well as those who were vaccinated in the follow-up period (under-fives) who also benefitted from less vaccine preventable illness among their school age siblings (5-9 years years old).

${ }^{34}$ The female file has somewhat richer data than the household file (e.g. anthropometrics) but is only for ever married women in most years except 1998.
} 
effect. To do so I use the years of schooling variable, which has a range from 0 to 20 and derive from that those who have received no school, those who obtained at least the compulsory education amount ( 5 years of primary school) and years of education above the compulsory cutoff. Similar to the main results, I include those who remain in province of birth or childhood to reduce measurement error in treatment assignment. I compare individuals born between 1971 and 1980 in the 2008 DHS to those born between 1961 to 1970 in the 1998 DHS (ages 28 to 37). This treatment group was chosen since these individuals would have been just outside the age eligible window for vaccination at the time of the campaign. I define the spillover and control cohort over a longer period of time than the census because of the smaller overall sample size and because there is more measurement error in the definition of treatment in the DHS since I cannot recreate sibship structure during the campaign ${ }^{35}$

Table 8 estimates equation (4). Moving across the columns, the results suggest that the spillover effects of the campaign induced women to attend school (on the extensive margin) and complete at least compulsory education. On the other hand, in column (3) there is no compelling evidence the campaign had a gender-specific spillover impact on years of education beyond the compulsory cutoff. Indeed, beyond compulsory education, the total spillover effect is negative, though the comparator group includes those that completed primary school.

Table 8. Estimates of the Spillover Effects: Evidence from DHS

\begin{tabular}{lccc}
\hline Dependent Variable & No Education & $\begin{array}{c}\text { Compulsory } \\
\text { Education }\end{array}$ & $\begin{array}{c}\text { Additional Years } \\
\text { Beyond Compulsory }\end{array}$ \\
\hline VPD Prevalence*PostSpillover & -0.0048 & $(2)$ & $(3)$ \\
VPD Prevalence *PostSpillover*Girl & $(0.0039)$ & 0.0038 & -0.196 \\
& $-0.0221^{* *}$ & $0.0174^{*}$ & $(0.126)$ \\
Sum of Above & $(0.0109)$ & $(0.0089)$ & 0.0143 \\
& $-0.0269 * * *$ & $0.022^{* *}$ & $(0.112)$ \\
Observations & $(0.009)$ & $(0.008)$ & $-0.181 * *$ \\
R-squared & 7,698 & 7,698 & $(0.086)$ \\
Year of Birth Fixed Effects & 0.3092 & 0.3115 & 7,698 \\
Birth Province Fixed Effects & Yes & Yes & 0.2099 \\
No. Clusters & Yes & Yes & Yes \\
Mean Dependent Variable & 67 & 67 & Yes \\
\hline
\end{tabular}

\footnotetext{
${ }^{35}$ Having two censuses five years apart is particularly advantageous for examining spillover effects. The spillover cohorts across the censuses (1970-1974 for the control and 1975-1979 for the treatment) can be fairly close in time and age. The DHS corroborates the census findings while providing a finer outcome measure than in the census.
} 
Notes: OLS estimates of equation (4) using the Turkish Demographic and Health Surveys household files. The outcome in column (1) is a binary variable equal to one if the respondent reported zero years of education. The outcome in column (2) is a binary variable equal to one if the respondent completed at least compulsory education (education years $>=5$ ). The outcome in column (3) is years of education beyond the compulsory amount of five years. Province of birth and year of birth fixed effects interacted with gender are included in every specification. Regressions are weighted using DHS provided household weights. Standard errors clustered on the birth province level.

$* * * * * *$ represents significance at the 10,5 , and 1 percent level, respectively.

\subsubsection{Enrollment Statistics}

Enrollment numbers by gender, grade and year are available from the National Education Statistics of Formal Education collected by the Turkish Government. I examine how the ratio of gender parity in primary level five enrollment (corresponding to children age 11) changes over time. Children in this age range would have been eligible caretakers for sick children if parental time inputs were insufficient yet should not have been direct recipients of the vaccines. I regress the enrollment ratio of girls and boys on the interaction of baseline vaccine preventable disease and a post dummy for 1985 (as in equation (21)) as well as province and year fixed effects. Figure 7 shows how the ratio evolves over time. The results from this regression yield a point estimate 0.016 and a standard error of 0.006 .

\section{Figure 7. Enrollment Ratio By Gender}

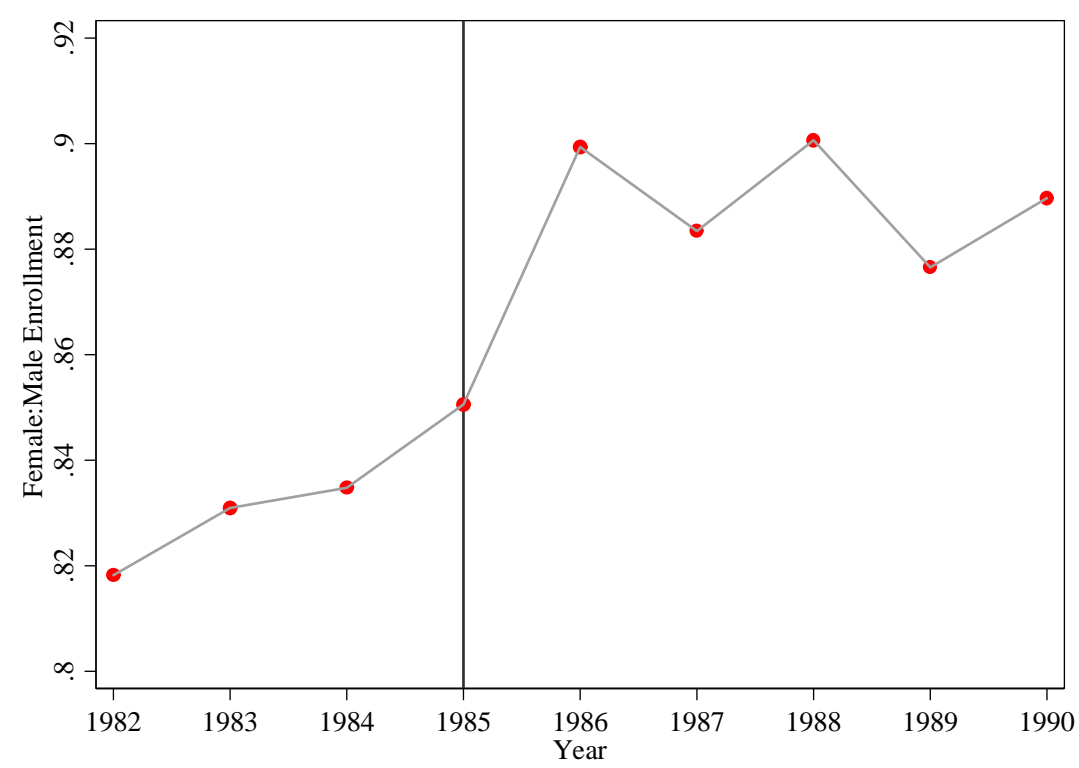

Notes: Ratio of female to male enrollment in primary school grade 5. Children at this grade are approximately 11 years of age and the youngest (11 in 1990) would have been on the cusp of eligibility for the campaign. Data are taken from the National Education Statistics of Turkish Government. 


\subsection{Alternative Explanations for Gendered Spillover Effects}

There are several competing theories that might explain the gendered effects on health and human capital presented above. First, poor health is a negative income shock for a household (Robinson and Yeh, 2011). When children are sick less often, and assuming girls' schooling is more income elastic than boys', parents who would not educate girl children in lean times may now have the resources to do so. However, evidence supporting the income mechanism is scant. To start, most families in the 1993 Turkish DHS treated children with low-cost medical therapies (e.g. antibiotics and oral rehydration therapy (ORT)) or home remedies for common child ailments (respiratory and diarrheal symptoms). For more serious manifestations of disease that are more costly to treat, over $90 \%$ of hospitalizations for pneumonia and dehydration took place in the heavily subsidized public sector. Yet the time costs to care for sick young children are not trivial as described below. Empirically, the campaign does not affect the professional status of either parent or their labor force participation (see Appendix Table B4).

Taste-based discrimination provides another competing explanation for the results. A convenient way to model such discrimination is to assume that there is a higher health threshold to educate girls than boys or to assume that families place higher weights on boy children ${ }^{36}$ Indeed, Appendix Table B5 demonstrates the effect of disability on literacy is more negative for girls than boys and this could be a possible reason for the gendered direct effects of the campaign demonstrated in Tables 5 and 6 . Although, taste-based discrimination would reinforce these findings (or potentially explain the gendered division of intrahousehold production), on its own, it fails to predict spillover benefits accruing only to older sisters.

Epidemiological spillovers are the most likely alternative explanation for my results. If older sisters are spending a substantial amount of time with younger siblings, they would also receive the greatest health benefits from the reduction in contagious disease once those young children are vaccinated. Although difficult to disprove, since the 1990 census does not include disability, it must be recognized that the epidemiological argument nests the hypothesis I test above, namely, that older sisters are doing much more caretaking which places them at heightened risk. However, given the U-shaped pattern of morbidity from infectious diseases - with school-age children typically having mild manifestations and most school-aged kids already possessing immunity via vaccination or direct disease exposure, the health benefits of the campaign for this population would have been limited ${ }^{37}$

\footnotetext{
${ }^{36}$ See Alesina and Ferrara (2014) for a model of different threshold effects applied to judicial racial discrimination. In the extreme, it could be that girls will only be educated if they are not disabled but boys will always be educated despite disability.

${ }^{37}$ For example, the age-specific complication rate of measles (which is the most prevalent and well documented of all vaccine preventable illnesses) demonstrates a stark U-shaped pattern, with infants and young toddlers having the highest complication rate $(41.4 \%)$ compared to those in the 10-19 year old range ( $12.8 \%$ ) or older adults $(34.4 \%)$ (Orenstein, Perry, and Halsey, 2004). Measles is so highly contagious that most middle school age children would have already been naturally exposed, and exposure to naturally occuring measles virus is considered to confer lifelong immunity Centers for Disease Control and Prevention.
} 


\subsection{Under-Five Morbidity in Developing Countries and the Pro- tective Effect of Immunization}

For the mechanism outlined above to be plausible, it must be that children under-five are sick either acutely but frequently or chronically; that such sickness leads to health-seeking and caretaking behaviors which place increasing demands on a mother's time, that daughters are viewed as substitute mothers and that sickness can be interrupted by targeted policies which improve child health, such as an immunization campaign. According to the 1993 Turkish DHS, approximately $51 \%$ of children under-five had one or more illness episodes in the two week interval preceding the interview. These illness episodes included diarrhea, fever and cough. To assess the correlation between vaccination status and illness, I regressed an indicator for any illness in the last two weeks on gender of child, age of child and number of vaccines received. The vaccines included were those distributed during the campaign: DPT, measles and polio, as well as BCG (Bacille Calmette Guerin), a vaccination against tuberculosis. Children under-five were 2 percentage points less likely to experience an illness in the last two weeks for each additional vaccine they had received (coefficient of -0.021 and standard error of 0.004). Sex and age of child were also statistically significant, with older age and girl sex suggestive of a protective effect ${ }^{38}$ Based on these results, a child who was fully vaccinated during the campaign had a 14 percentage point reduction in acute illness episodes.

Not all illness episodes require trips to the doctor. Among children with episodes of cough or fever in the last two weeks, $63 \%$ received some treatment and $35 \%$ received medical treatment. For episodes of diarrhea, $72 \%$ of children received treatment though only $25 \%$ received medical treatment. However, it's important to note that many effective interventions are time-intensive. ORT for diarrhea is one such example. Infants and young children must be fed the solution every few minutes 39

In addition to acute illness, vaccine preventable illnesses can rarely result in chronic disease with ongoing caregiving needs. Paralysis from polio is perhaps the most well-known. It is estimated that 1 in 4 people become symptomatic with polio virus though only 1 in 200 will be paralyzed and only 2 to $10 \%$ of those with paralysis die due to difficulty breathing (Centers for Disease Control and Prevention, 2015). Measles can lead to a severe pneumonia and, in 1 of every 1000 children, an encephalitis that can result in deafness, brain damage and intellectual disability. Hypoxia and ensuing brain sequelae can also rarely occur from the violent cough associated with pertussis.

Other studies have found evidence consistent with the notion that girls step in to perform 2013).

\footnotetext{
${ }^{30}$ Assessing which vaccines are most protective is beyond the scope of the current paper.

${ }^{39}$ Approximately $7.8 \%$ of all children under-five had visited a hospital for treatment. If a child is hospitalized, many developing countries rely on mothers to provide inpatient nursing, including meal preparation, medication administration and laundry.
} 
housekeeping and childcare chores when a mother is absent. Gertler, Levine, and Ames (2004) using data from Indonesia, found that although daughters in general were not more likely than sons to drop out of school if a parent died, daughters with younger siblings were more likely to do so. They relate this finding to ethnographic literature in Indonesia which places the burden of household duties on older girls. Such norms are also prevalent in Turkey, especially during the time of the campaign: According to Fernea (1995, p. 263), "Young girls help their mothers with the housework and take care of younger siblings." The interaction of norms, technology and illness can plausibly explain the gender-specific spillover effect observed in the analysis.

\section{$6 \quad$ Policy Implications and Concluding Remarks}

Several studies in economics have documented unintended consequences of technological fixes for public health problems (Field, Glennerster, and Hussam, 2011; Lakdawalla, Sood, and Goldman, 2006). This article investigated the impact of the Turkish National Immunization Campaign on health and human capital through the lens of cultural norms and incorporating disease dynamics. The campaign was prompted by innovation in vaccine development and delivery and was instituted with broad-based political and religious support. Vaccination distribution was near universal but occurred in an environment where gender roles were concretized early.

Although the documented gains in vaccine coverage for under-five children were impressive, I find no evidence that the intended reduction in infant mortality was realized. The impacts on disability and human capital were significant and the latter effect was not limited to the targeted population: older sisters of age-eligible recipients also benefitted relative to older brothers. The results were interpreted within a model of intrahousehold allocation of scarce time resources and specialization. Gender-specific spillover effects increased in the number of younger siblings and if the mother worked outside the home and were absent in the presence of older female caregivers and if younger children were not present - providing empirical support for the proposed mechanism. Although other forces for convergence could have been at play, the pattern of accentuation and attenuation of gendered spillover effects as the time budget of mothers tighten and slacken, respectively, is striking and its interpretation is consistent with the gendered division of household tasks commonly observed in microdata from low- and middle-income countries. The observation that girls gained compulsory education, but nothing more, points to important interactions between education and health policy.

As child survival continues to increase in developing countries, emphasis will gradually shift from decreasing mortality to reducing morbidity. The spillover effects of the campaign on the human capital of older girl siblings suggests that individuals most often tasked with caring for young children when they are ill will also disproportionately benefit from their 
health improvement. These unanticipated outcomes provide yet another reason to look beyond mortality to other outcomes (namely, education and gender equity) when modeling or assessing the full impact of the broad-based distribution of early childhood health technologies in low-and middle-income countries 40

\footnotetext{
${ }^{40} \mathrm{~A}$ comparative cost effectiveness calculation of under-five vaccination on schooling is provided in Ap-
} pendix C. 


\section{References}

Adhvaryu, A., and A. Nyshadham (2014): "Endowments at Birth and Parents' Investments in Children," The Economic Journal, pp. 1-40.

Alesina, A., And E. Ferrara (2014): "A Test of Racial Bias in Capital Sentencing," American Economic Review, 104(11), 3397-3433.

Alesina, A., P. Giuliano, and N. Nunn (2013): "On the Origin of Gender Roles: Women and the Plough," The Quarterly Journal of Economics, 128(2), 469-530.

Almond, D. (2006): "Is the 1918 Influenza Pandemic Over? Long-term Effects of in Utero Influenza Exposure in the Post 1940 U.S. Population," Journal of Political Economy, 1114(4), 672-712.

Almond, D., And J. Currie (2011): "Killing Me Softly: The Fetal Origins Hypothesis," Journal of Economic Perspectives, 25(3), 153-72.

Alsan, M., A. Bhadelia, P. Foo, C. Haberland, and F. Knaul (2016): The Economics of Women's Health in Low- and Middle-Income Countriesvol. 3. World Scientific Publishing Co.

Alsan, M., A. Xing, P. Wise, G. Darmstadt, and E. Bendavid (2017): "Childhood Illness and the Gender Gap in Adolescent Education in Low- and Middle- Income Countries," Pediatrics, 140(1), e20163175.

Angrist, J. D., And J.-S. Pischke (2009): Mostly Harmless Econometrics: An Empiricist's Companion. Princeton University Press, 1 edn.

Barcellos, S. H., L. S. Carvalho, and A. Lleras-Muney (2014): "Child Gender and Parental Investments in India: Are Boys and Girls Treated Differently?," American Economic Journal: Applied Economics, 6(1), 157-89.

Barron, P., E. Buch, G. Behr, and N. Crisp (1987): "Mass Immunisation Campaign - Do They Solve the Problem?," South African Medical Journal, 72, 321-322.

Becker, G., And N. Tomes (1979): "An Equilibrium Theory of the Distribution of Income and Intergenerational Mobility," Journal of Political Economy, 86(6), 1153-1189.

Becker, G. S., W. H. Hubbard, and K. M. Murphy (2010): "Explaining the Worldwide Boon in Higher Education of Women," Journal of Human Capital, 4(3), 203-41.

Behrman, J. R. (1997): Handbook of Population and Family Economicschap. Chapter 4: Intrahousehold distribution and the Family. Elsevier. 
Behrman, J. R., R. A. Pollak, and P. Taubman (1982): "Parental Preferences and Provision for Progeny," Journal of Political Economy, 90(1), 52-73.

Berkes, N. (1998): The Development of Secularism in Turkey. Routledge, New York, NY, reissue edn.

Black, S., S. Breining, D. N. Figlio, J. Guryan, K. Karbownkik, H. S. Nielsen, J. Roth, And M. Simonsen (2017): "Sibling Spillovers," Discussion paper, NBER Working Paper 23062.

Black, S. E., And P. J. Devereux (2011): "Recent Developments in Intergenerational Mobility," Handbook of Labor Economics, 4, 1487-1541.

Bloom, D. E., D. Canning, and E. S. Shenoy (2012): "The Effect of Vaccination on Children's Physical and Cognitive Development in the Phillipines," Applied Economics, 44(21), 2777-2783.

CARD, D. (1992): "Using Regional Variation in Wages to Measure the Effects of the Federal Minimum Wage," Industrial and Labor Relations Review, 46(1), 22-37.

Centers for Disease Control and Prevention (2013): "Vaccines Pink Book," Report, CDC, http://www.cdc.gov/vaccines/vpd-vac/measles/downloads/dis-measles-coloroffice.pdf, accessed July 7, 2015.

(2015): "What is Polio?," Discussion paper, CDC.

Clark, S. (2000): "Son Preference and Sex Composition of Children: Evidence from India," Demography, 37(1), 95-108.

Cunha, F., And J. Heckman (2007): "The Technology of Skill Formation," American Economic Review, 97(2), 31-47.

Duflo, E. (2003): "Grandmothers and Granddaughters: Old Age Pension and Intrahousehold Allocation in South Africa," World Economic Review, 17(1), 1-25.

Duflo, E. (2012): "Women Empowerment and Economic Development," Journal of Economic Literature, 50(4), 1051-1079.

Fernea, E. W. (1995): Children in the Muslim Middle East. University of Texas Press, Austin.

Field, E., R. Glennerster, and R. Hussam (2011): "Throwing the Baby Out with the Drinking Water: The Unintended Consequences of Arsenic Mitigation Efforts in Bangladesh," Discussion paper, Duke University Working Paper. 
Fisek, N. H., And R. ERdal (1985): "Primary health care: a continuous effort.," in World Health Forum, vol. 6, pp. 230-1.

Franzese, R., AND C. KAM (2007): Modeling and Interpreting Interactive Hypotheses in Regression Analysis: A Refresher and Some Practical Advice. University of Michigan Press, 1 edn.

Gertler, P., D. I. Levine, and M. Ames (2004): "Schooling and Parental Death," The Review of Economics and Statistics, 86(1), 211-225.

Goldin, C. (1992): Understanding the Gender Gap: An Economic History of American Women. Oxford University Press.

ICF International (2003, 1998, 1993): "Demographic and Health Surveys (various)," [datasets], ICF International [Distributor], Calverton, Maryland.

Ilkkaracan, I., And R. Selim (2007): "The Gender Wage Gap in the Turkish Labor Market," LABOUR, 21(3), 563-593.

International Labor Organization (2016): "Gender and Child Labour in Agriculture," accessed 24 January 2016.

International Trade Centre (2011): "Women in Cotton: Results of A Global Survey," Technical Paper SC-11-208.E, International Trade Centre.

Jensen, R. (2000): "Agricultural Volatility and Childrens Investments," The American Economic Review, 90(2), 399-404.

Kaiser Family Foundation (2014): "Data Note: Balancing on Shaky Ground: Women, Work and Family Health," Brief, The Henry J. Kaiser Foundation.

Kirdar, M., M. D. Tayfur, and İ. Koç (2011): "The Effect of Compulsory Schooling Laws on Teenage Marriage and Births in Turkey," Discussion Paper Series 5887, IZA.

Lakdawalla, D., N. Sood, and D. Goldman (2006): "HIV Breakthroughs and Risky Sexual Behavior," The Quarterly Journal of Economics, 121(3), 1063-1102.

LeVine, R., And M. Rowe (2009): "Maternal Literacy and Child Health in Less-Developed Countries: Evidence, Processes, and Limitations," Journal of Developmental and Behavioral Pediatrics, 30(4), 340-349.

Miguel, E., And M. Kremer (2004): "Worms: Identifying Impacts on Education and Health in the Presence of Treatment Externalities," Econometrica, 72(1), 159-217. 
Mikkelsen, L., A. Lopez, And D. Phillips (2015): "Why Birth and Death Registration Really Are Vital Statistics Development," Human development reports, UNDP, http://hdr.undp.org/en/content/why-birth-and-death-registration-really-are-E2

Miller, G., and B. P. Urdinola (2010): "Cyclicality, Mortality, and The Value of Time: The Case of Coffee Price Fluctuations and Child Survival in Colombia," Journal of Political Economy, 118(1), 113-155.

Mina, M. J., C. J. E. Metchlf, R. L. De Swart, A. Osterhaus, and B. T. GrenFELL (2015): "Long-term measles-induced immunomodulation increases overall childhood infectious disease mortality," Science, 348(6235), 694-699.

Minnesota Population Center (2017): "Integrated Public Use Microdata Series International: Version 6.5 [dataset]," [Machine-readable database].

Orenstein, W. A., R. T. Perry, and N. A. Halsey (2004): "The Clinical Significance of Measles: A Review," Journal of Infectious Diseases, 189(Supplement 1), S4-S16.

OzIER, O. W. (Forthcoming): "Exploiting Externalities to Estimate the Long-Term Effects of Early Childhood Deworming," AEJ: Applied Economics.

Parman, J. (2013): "Childhood Health and Sibling Outcomes: The Shared Burden and Benefit of the 1918 Influenza Pandemic," Working Paper 19505, National Bureau of Economic Research.

Pitt, M. M., M. R. Rosenzweig, and M. N. Hassan (2012): "Human Capital Investment and the Gender Division of Labor in a Brawn-Based Economy," American Economic Review, 102(7), 3531-3560.

Robinson, J., And E. Yeh (2011): "Transactional Sex as a Response to Risk in Western Kenya," AEJ Applied Economics, 3(1), 35-64.

Rosenzweig, M., And M. Pitt (1990): "Estimating the Intrahosuehold Incidence of Illness: Child Health and Gender Inquality in the Allocation of Time," International Economic Review, 31(4), 969-989.

Rosenzweig, M. R. (1980): "Household and Non-Household Activities of Youths: Issues of Modelling, Data and Estimation Strategies," Population and Employment Working Papers 204187, World Employment Progamme Research.

Schultz, T. P. (2002): "Why Governments Should Invest more in Girls," World Development, 30(2), 207-225. 
Topalli, R. (2015): "Primary Health Care in Turkey A Brief History and Current Situation," [powerpoint slides], Kocaeli University Medical School - Department of Family Medicine.

Tunçbilek, E., S. Cerit, T. Unalan, B. Akadli, and A. Toros (1985): "Report on the Baseline Survery for the 1985 Turkish National Immunization Campaign," Turkish Journal of Population Studies, 7, 5-26.s.

TunçBilek, E ET AL. (1986): "The Vaccination Situation of Children Between 0-5 Years of Age After the Accelerated Vaccination Campaign and a Comparison with Pre-Campaign Results," Turkish Journal of Population Studies, 8, 5-36.s.

Turkish Statistical Institute (1982): "National Education Statistics," Dataset, Office of the Prime Minister.

TurkStat (1983, 1989): "Türkiye Istatistik Yilligi,” Dataset, Turkish Government.

UNICEF (1985): "The State of the World's Children 1985," Newsline, UNICEF.

(1986): "Rapid Assessment: Turkish National Immunization Campaign of 1985," Newsline, UNICEF.

UNICEF (2008): "Legislative Reform on Child Domestic Labour: A Gender Analysis," Legislative reform initiative - paper series, Division of Policy and Planning.

VogL, T. (2013): "Marriage Institutions and Sibling Competitiion Evidence From Souh Asia," The Quarterly Journal of Economics, 128(3), 1017-1072.

Wolfson, L., R. F. Grais, F. J. Luquero, M. E. Birmingham, and P. M. Strebel (2009): "Estimates of measles case fatality ratios: a comprehensive review of communitybased studies," International Journal of Epidemiology, 38(1), 192-205.

World Bank (2012): "World Development Report 2012: Gender Equality and Development," .

Yi, J., J. J. Heckman, J. Zhang, and G. Conti (2015): "Early Health Shocks, Intrahousehold Resource Allocation and Child Outcomes," The Economic Journal, 125(588), F347-F371. 